\title{
Dynamic Pricing and Learning: \\ Historical Origins, Current Research, and New Directions
}

\author{
A.V. den Boer \\ University of Twente, P.O. Box 217, 7500 AE Enschede \\ a.v.denboer@utwente.nl
}

This version: October 23, 2013

\begin{abstract}
Dynamic pricing and learning is a research topic that has received a considerable amount of attention in recent years, from different scientific communities: operations research and management science, marketing, economics, econometrics, and computer science. We survey these literature streams: we provide a brief introduction to the historical origins of quantitative research on pricing and demand estimation, point to different subfields in the area of dynamic pricing, and provide an in-depth overview of the available literature on dynamic pricing and learning. We discuss relations with methodologically related research areas, and identify several important directions for future research.
\end{abstract}

\section{Introduction}

Dynamic pricing is the study of determining optimal selling prices of products or services, in a setting where prices can easily and frequently be adjusted. This applies to vendors selling their products via Internet, or to brick-and-mortar stores that make use of digital price tags. In both cases, digital technology has made it possible to continuously adjust prices to changing circumstances, without any costs or efforts. Dynamic pricing techniques are nowadays widely used in various businesses, and in some cases considered to be an indispensable part of pricing policies.

Digital sales environments generally provide firms with an abundance of sales data. This data may contain important insights on consumer behavior, in particular on how consumers respond to different selling prices. Exploiting the knowledge contained in the data and applying this to dynamic pricing policies may provide key competitive advantages, and knowledge how this should be done is of highly practical relevance and theoretical interest. This consideration is a main driver of research on dynamic pricing and learning: the study of optimal dynamic pricing in an uncertain environment where characteristics of consumer behavior can be learned from accumulating sales data.

The literature on dynamic pricing and learning has grown fast in recent years, with contributions 
from different scientific communities: operations research and management science (OR/MS), marketing, computer science, and economics / econometrics. This survey aims at bringing together the literature from these different fields, and at highlighting some of the older (and sometimes forgotten) literature where many important results and ideas already can be found.

A few literature reviews on dynamic pricing and learning do already exist. Araman and Caldentey (2011) and Aviv and Vulcano (2012, Section 4) review in detail a number of recent studies, mostly from the OR/MS community, and Christ (2011, Section 3.2.1) contains an elaborate discussion of a selection of demand learning studies. Our survey complements these publications by aiming at a larger scope, and, although our main focus is on the OR/MS literature, we also address relevant contributions from computer science, marketing, economics and econometrics.

This survey reviews the literature on dynamic pricing with demand uncertainty. We discuss how this is embedded in the literature on dynamic pricing in general, but do not review all relevant research topics associated with dynamic pricing; for this we refer to Bitran and Caldentey (2003), Elmaghraby and Keskinocak (2003), Talluri and van Ryzin (2004), Phillips (2005), Heching and Leung (2005), Gönsch et al. (2009), Rao (2009), Chenavaz et al. (2011), Deksnyte and Lydeka (2012) and Özer and Phillips (2012). We focus on studies where selling price is a control variable; we only scarcely discuss learning in capacity-based revenue management (Talluri and van Ryzin, 2004) or learning in newsvendor/inventory control problems. Neither do we consider mechanism design (Harris and Raviv, 1981, Maskin and Riley, 1984) or auction theory with incomplete information (see e.g. Segal (2003), Babaioff et al. (2011) and the references therein), although there are some similarities with dynamic pricing and learning. Most of the studies that we discuss are written from an (online) retailer perspective. We do not dive into specific details associated with particular application area such as pricing in queueing or telecommunication environments (Mutlu et al., 2012), road pricing (de Palma et al., 2006, Tsekeris and Voß, 2009, Lou, 2013), or electricity pricing (Garcia et al., 2005, Roozbehani et al., 2010), to name a few. Finally, this survey focuses on studies where the seller learns about the demand function, and not on studies where buyers are learning (Bergemann and Välimäki, 1997, Ottaviani, 1999, Caminal and Vives, 1999, Schlee, 2001, Bose et al., 2006, Bhalla, 2012, Ifrach et al., 2012).

This survey is organized as follows. We review in Section 2 some of the pioneering historical work on pricing and demand estimation, and discuss how this work initially was difficult to apply in practice. In Section 3 we sketch important references and developments for dynamic pricing in general, and in Section 4 we focus on the literature that specifically deals with dynamic pricing and learning. Connections between dynamic pricing and related research areas are addressed in Section 5, and related new research directions are discussed in Section 6.

\section{Historical Origins of Pricing and Demand Estimation}

Dynamic pricing with learning can be regarded as the combined application of two research fields: (1) statistical learning, specifically applied to the problem of estimating demand functions, and

(2) price optimization. Both these fields are already quite old, dating back more than a century. 
In this section we briefly describe the historical fundaments out of which dynamic pricing and learning has emerged, by pointing to some key references on static pricing and estimating demand functions that have been important in the progress of the field.

\subsection{Demand functions in pricing problems}

Cournot (1838) is generally acknowledged as the first to use a mathematical function to describe the price-demand relation of products, and subsequently solve the mathematical problem of determining the optimal selling price. As vividly described by Fisher (1898), such an application of mathematical methods to study an economical problem was quite new and controversial at the time, and the work was neglected for several decades. Cournot showed that if $F(p)$ denotes the demand as a function of price $p$, where $F(p)$ is continuous, decreasing in $p$, and $p F(p)$ is unimodal, then the price that maximizes the revenue $p F(p)$ can be found by equating the derivative of $p F(p)$ to zero. If $F(p)$ is concave there is a unique solution, which is the optimal price (this is contained in Chapter IV of Cournot (1838)). In this way, Cournot was the first to solve a "static pricing" problem by mathematical methods.

\subsection{Demand estimation}

To make theoretical knowledge on optimal pricing theory applicable in practical problems, one needs to have an estimate of the demand function. The first known empirical work on demand curves is the so-called King-Davenant Law (Davenant, 1699) which relates the supply and price of corn (see Creedy, 1986, for an exposition on the origins of this work). More advanced research on estimating demand curves, by means of statistical techniques such as correlation and linear regression, took off in the beginning of the $20^{\text {st }}$ century. Benini (1907), Gini (1910) and Lehfeldt (1914) estimate demand curves for various goods as coffee, tea, salt, and wheat, using various curve-fitting methods. Further progress on methodology was made, among others, by Moore (1914, 1917), Wright (1928) and Tinbergen (1930); the monumental work of Schultz (1938) gives a thorough overview of the state-of-the-art of demand estimation in his time, accompanied by many examples. Further references and more information on the historical progress of demand estimation can be found in Stigler (1954, section II), Stigler (1962, particularly section iii), Brown and Deaton (1972), Christ (1985), and Farebrother (2006). A small sample of the many contemporary studies on demand estimation in different contexts is Berry et al. (1995), McFadden and Train (2000) and Bajari and Benkard (2005).

\subsection{Practical applicability}

Estimating demand curves of various products was in first instance not aimed at profit optimization of commercial firms, but rather used to support macro-economic theories on price, supply, and demand. Application of the developed methods in practical problems was initially far away. An illustrative quote is from Hicks (1935), who doubted the possibilities of applying the theory of 
monopoly pricing on practical problems, exactly because of the difficulty of estimating the demand curve:

It is evidently the opinion of some of the writers under discussion that the modern theory of monopoly is not only capable of throwing considerable light on the general principles underlying an individualistic economic structure, but that it is also capable of extensive use in the analysis of particular practical economic problems, that is to say, in applied economics. Personally, I cannot but feel sceptical about this. [...] There does not seem to be any reason why a monopolist should not make a mistake in estimating the slope of the demand curve confronting him, and should maintain a certain output, thinking it was the position which maximized his profit, although he could actually have increased his profit by expanding or contracting. (Hicks, 1935, page 18,19).

Hawkins (1957) reviews some of the attempts made by commercial firms to estimate the demand for their products. Most of these attempts were not successful, and suffered from difficulties of obtaining sufficiently many data for reliable estimates, and of changes in the quality of the product and the prices of competitors. Even a very detailed study of General Motors on automobile demand ends, somewhat ironically, with:

The most important conclusion from these analyses of the elasticity of demand for automobiles with respect to price is that no exact answer to the question has been obtained. (Horner et al., 1939, p. 137).

In view of these quotations, it is rather remarkable that dynamic pricing and learning has nowadays found its way in practice; many applications have been reported in various branches such as airline companies, the hospitality sector, car rental, retail stores, internet advertisement, and many more. A main cause for this is the fact that nowadays historical sales data is typically digitally available. This significantly reduces the efforts required to obtain sufficiently accurate estimates of the demand function. In addition, whenever products are sold via the Internet or using digital price tags, the costs associated with adjusting the prices in response to updated information or changed circumstances are practically zero. In contrast, a price-change in the predigital era would often induce costs, for example because a new catalog had to be printed or price tags had to be replaced. For a detailed study on such price-adjustment costs we refer to Zbaracki et al. (2004) and the references therein. Slade (1998) and Netessine (2006) are two studies that consider dynamic pricing with costly price adjustments.

\section{Dynamic Pricing}

In this section we discuss the literature on dynamic pricing. Because of the huge amount of literature on this subject, we can not give a complete overview of the field. Instead, we briefly describe some of the major research streams and key references, in order to provide a context in which one can position the literature on dynamic pricing with learning discussed in Section 4. For a more elaborate overview of the vast literature on dynamic pricing, we refer to the books Talluri and van Ryzin (2004), Phillips (2005), Rao (2009), Özer and Phillips (2012), and the reviews 
by Bitran and Caldentey (2003), Elmaghraby and Keskinocak (2003), Heching and Leung (2005), Gönsch et al. (2009), Seetharaman (2009), Chenavaz et al. (2011) and Deksnyte and Lydeka (2012).

The literature on dynamic pricing by a monopolist firm can roughly be classified as follows:

- Models where the demand function is dynamically changing over time.

- Models where the demand function is static, but where pricing dynamics are caused by the inventory level.

In the first class of models, reviewed in Section 3.1, the demand function changes according to changing circumstances: for example, the demand function may depend on the time-derivative of price, on the current inventory level, on the amount of cumulative sales, on the firm's pricing history, et cetera. In the second class of models, reviewed in Section 3.2, it is not the demand function itself that causes the price dynamics: a product offered in two different time periods against the same selling price is expected to generate the same amount of average demand. Instead, the price dynamics are caused by inventory effects, more concretely by changes in the marginal value of inventory. Naturally, it is also possible to study models that fall both in classes, where both the demand function is dynamically changing and the price dynamics are influenced by inventory effects; some of this literature is also reviewed in Section 3.2.

\subsection{Dynamic pricing with dynamic demand}

\subsubsection{Demand depends on price-derivatives}

Evans (1924) is one of the first to depart from the static pricing setting introduced by Cournot (1838). In a study on optimal monopoly pricing, he assumes that the (deterministic) demand is not only a function of price, but also of the time-derivative of price. This models the fact that buyers do not only consider the current selling price in their decision to buy a product, but also anticipated price changes. The purpose of the firm is to calculate a price function, on a continuous time interval, that maximizes the profit. The problem is solved explicitly using techniques from calculus of variations. Various extensions to this model are made by Evans (1925), Roos (1925, 1927a,b, 1934), Tintner (1937), and Smithies (1939). Thompson et al. (1971) study an extended version of the model of Evans (1924), where optimal production level, investment level, and output price have to be determined. Closely connected to this work is Simaan and Takayama (1976), who consider a model where supply is the control variable, and where the time-derivative of price is a function of the current supply and current price. Methods from control theory are used to derive properties of the optimal supply path.

\subsubsection{Demand depends on price history}

A related set of literature considers the effect of reference prices on the demand function. Reference prices are perceptions of customers about the price that the firm has been charging in the past; see Mazumdar et al. (2005) for a review on the subject. A difference between the reference price 
and the actual selling price influences the demand, and, as a result, each posted selling price does not only affect the current demand but also the future demand. Dynamic pricing models and properties of optimal pricing strategies in such settings are studied, among others, by Greenleaf (1995), Kopalle et al. (1996), Fibich et al. (2003), Heidhues and Köszegi (2005), Popescu and Wu (2007) and Ahn et al. (2007).

\subsubsection{Demand depends on amount of sales}

Another stream of literature on dynamic pricing emerged from diffusion and adoption models for new products. A key reference is Bass (1969), and reviews of diffusion models are given by Mahajan et al. (1990), Baptista (1999), and Meade and Islam (2006). In these models, the demand for products does not only depend on the selling price, but also on the amount of cumulative sales. This allows modeling several phenomena related to market saturation, advertisement, word-ofmouth effects, and product diffusion. Robinson and Lakhani (1975) study dynamic pricing in such a model, and numerically compare the performance of several pricing policies with each other. Their work stimulated much further research on optimal dynamic pricing policies, see e.g. Clarke et al. (1982), Kalish (1983), Clarke and Dolan (1984), and the references therein. The models studied in these papers are deterministic, and somewhat related to the literature following Evans (1924): both types of pricing problems are solved by principles from optimal control theory, and the optimal pricing strategy is often given by the solution of a differential equation.

Chen and Jain (1992), Raman and Chatterjee (1995), and Kamrad et al. (2005) extend these models by incorporating randomness in the demand. In Chen and Jain (1992), the demand is determined by a finite-state Markov chain for which each state corresponds to a deterministic demand function that depends on price and cumulative sales. The optimal price path is characterized in terms of a stochastic differential equation, and compared with the optimal policy in a fully deterministic setting. Raman and Chatterjee (1995) model uncertainty by adding a Wiener process to the (known) deterministic component of the demand function. They characterize the pricing policy that maximizes discounted cumulative profit, and compare it with the optimal price path in the fully deterministic case. Under some specific assumptions, closed form solutions are derived. Similar models that incorporate demand uncertainty are analyzed by Kamrad et al. (2005). For various settings they provide closed-form solutions of the optimal pricing policies.

\subsection{Dynamic pricing with inventory effects}

There are two important research streams on dynamic pricing models where the dynamics of the optimal pricing policy are caused by the inventory level: (i) "revenue management" type of problems, where a finite amount of perishable inventory is sold during a finite time period, and (ii) joint pricing and inventory-procurement problems. 


\subsubsection{Selling a fixed, finite inventory during a finite time period}

In this stream of literature, a firm is assumed to have a certain number of products at its disposal, which are sold during a finite time period. There is no replenishment: inventory that is unsold at the end of the selling horizon is lost, and can not be transferred to another selling season. In these problems, the dynamic nature of optimal prices is not caused by changes in the demand function, but by the fact that the marginal value of remaining inventory is changing over time. As a result, the optimal selling price is not a fixed quantity, but depends on the remaining amount of inventory and the remaining duration of the selling season.

Kincaid and Darling (1963) may be the first to characterize and analyze the optimal pricing policy in such a setting. A more recent key reference is Gallego and van Ryzin (1994). They consider a continuous-time setting where demand is modeled as a Poisson process, with arrival rate that depends on the posted selling price. The pricing problem is formulated as a stochastic optimal control problem, and the optimal solution is characterized using the Hamilton-Jacobi-Bellman equation. A closed-form solution may in general not exist, but for a specific demand function a closed-form optimal solution is derived. The authors furthermore propose two heuristic pricing policies, provide bounds on their performance, and discuss various extensions to the model.

Numerous extensions and variations of the model by Gallego and van Ryzin (1994) have been studied: for example, settings with restrictions on the number of allowable prices or price changes (Feng and Gallego, 1995, Bitran and Mondschein, 1997, Feng and Xiao, 2000a,b), extensions to multiple products that share the same finite set of resources (Gallego and van Ryzin, 1997, Kleywegt, 2001) or multiple stores (Bitran et al., 1998).

Feng and Gallego (2000) and Zhao and Zheng (2000) characterize the optimal pricing policy in case of time dependent demand intensities; in these models, the price dynamics are caused both by inventory effects and by dynamic demand behavior.

The same holds for models that study strategically behaving customers: customers who, when arriving at the (online) store, do not immediately decide whether to buy the product, but instead wait for a while to anticipate possible decreases in the selling price. In contrast, so-called myopic customers instantly decide whether to buy the product at the moment they arrive at the store. In such settings, the demand at a certain moment depends on the past, present, and future selling prices. Dynamic pricing in view of strategic customers has received a considerable amount of research attention in recent years; a representative sample is Su (2007), Aviv and Pazgal (2008), Elmaghraby et al. (2008), Liu and van Ryzin (2008), Levin et al. (2009), Cachon and Swinney (2009) and Su (2010). Reviews of these literature are given by Shen and Su (2007) and Gönsch et al. (2012). These studies typically have a game-theoretic flavor, since both the firm and the strategic customers have a decision problem to solve, with contradicting interests.

\subsubsection{Jointly determining selling prices and inventory procurement}

A main assumption of the literature discussed above is that the initial capacity level is fixed. In many situations in practice this is a natural condition: the number of seats in an aircraft, rooms in 
a hotel, tables in a restaurant, or seats in a concert hall are all fixed for a considerable time period, and modifications in the capacity occur at a completely different time scale than dynamic price changes. In many other settings, however, the initial capacity is a decision variable to the firm; in particular, when the firm can decide how many items of inventory should be produced or purchased. Pricing and inventory management can then be considered as a simultaneous optimization problem.

This research field bridges the gap between the pricing and inventory management literature. Many different settings and models are subject to study, with different types of production, holding and ordering costs, different replenishment policies (periodic or continuous), finite or infinite production capacity, different models for the demand function, et cetera. Extensive reviews of the literature on simultaneous optimization of price and inventory decisions can be found in Eliashberg and Steinberg (1993), Federgruen and Heching (1999), Elmaghraby and Keskinocak (2003, Section 4.1), Yano and Gilbert (2005), Chan et al. (2004), and Chen and Simchi-Levi (2012).

\section{Dynamic Pricing and Learning}

In the static monopoly pricing problem considered by Cournot (1838), the demand function is deterministic and completely known to the firm. These assumptions are somewhat unrealistic in practice, and eventually it was realized that demand uncertainty should be incorporated into the problem. One of the first to pursue this direction is Mills (1959), who assumes that the demand is the sum of a random term with zero mean and a deterministic function of price. He studies how a monopolist firm that sells finitely many products in a single time period should optimally set its production level and selling price. Further extensions of this model and properties of pricing problems with random demand are studied by Karlin and Carr (1962), Nevins (1966), Zabel (1970), Baron (1970, 1971), Sandmo (1971) and Leland (1972). An important research question in these studies is how the firm's optimal decisions are influenced by the demand uncertainty and by the firms' attitude towards risk (risk-neutral, risk-averse, or risk-preferred).

In the models mentioned above, the expected demand as a function of the selling price is still assumed to be completely known by the firm, which makes these models somewhat unrealistic and not usable in practice. The common goal of the literature on dynamic pricing and learning is to develop pricing policies that take the intrinsic uncertainty about the relation between price and expected demand into account.

In the next two sections we discuss the literature on dynamic pricing and learning. Section 4.1 considers the literature on the problem of a price-setting firm with infinite inventory and unknown demand function. This basically is the monopoly pricing problem described in Section 2.1, with uncertainty about the demand function. The full-information case of this problem is static; the price dynamics are completely caused by the fact that the firm learns about the price-demand relation through accumulating sales data. Section 4.2 discusses literature on pricing policies for firms selling a fixed, finite amount of inventory, with unknown demand function. For this problem, the full-information case is already dynamic by itself, as discussed in Section 3.2, and the learning aspect of the problem provides an additional source of the price dynamics. 


\subsection{No inventory restrictions}

\subsubsection{Early work}

The first analytical work on dynamic monopoly pricing with unknown demand curve seems to have been presented on August 2, 1954, at the 16th European meeting of the Econometric Society (Hansen, 1955), by F. Billström, H. Laadi, and S.A.O. Thore, with contributions from L.O. Friberg, O. Johansson, and H.O.A. Wold. A mimeographed report Billström et al. (1954) of the presented work has not been published in a journal, but an English reprint has appeared in Billström and Thore (1964) and Thore (1964). These two works discuss the problem of a monopolist facing a linear demand curve that depends on two unknown parameters. Thore (1964) proposes to use a dynamic pricing rules that satisfies $\operatorname{sign}\left(p_{t}-p_{t-1}\right)=\operatorname{sign}\left(\left(p_{t-1}-p_{t-2}\right)\left(r_{t-1}-r_{t-2}\right)\right)$, where $p_{t}$, $r_{t}$ denote the price and revenue in period $t$. This models the following intuition: if a previous price increase led to an increase in revenue, the price will again be increased; otherwise it will be decreased. Similarly, if a previous price decrease led to an increase in revenue, the price will again be decreased; otherwise, it will be increased. In addition, Thore (1964) proposes to let the magnitude of the price adjustment depend on the difference between the last two revenue observations. He specifies two pricing rules in detail, and analyzes convergence properties of the resulting dynamical systems. Billström and Thore (1964) perform simulation experiments for one of these pricing rules, both in a deterministic demand setting and in a setting where a normally distributed disturbance term is added to the demand. They also extend the model to incorporate inventory replenishment, and provide a rule of thumb for the optimal choice of a constant appearing in the pricing rule.

These studies emerging from the Uppsala Econometrics Seminar have not received much research attention in subsequent years. Clower (1959) studies a monopolist firm facing a linear, deterministic demand function whose parameters may change over time. He discusses several priceadjustment mechanisms that may be applied by the firm to adapt its prices to changing situations. Baumol and Quandt (1964) propose rules of thumb for the monopolist pricing problem, and assess their performance by a set of numerical experiments. In their Appendix A they propose a pricing rule equal to one of the rules proposed by Thore (1964), although they are apparently unaware of that work. The authors investigate some convergence and stability properties of the resulting dynamical system, both in a discrete-time and continuous-time framework. Baetge et al. (1977) extend the simulation results of Billström and Thore (1964) to non-linear demand curves, and study the optimal choice of a constant appearing in the pricing rules. A final study in this line of research is from Witt (1986). He studies a model where a monopolist has to decide on price, output level in the current period and maximum output in the next period. Three decision rules are compared with each other via a computer simulation. In addition, their performance is compared with a laboratory experiment, where test subjects had to determine their optimal pricing strategy. 


\subsubsection{Bayesian approaches}

Several authors study the dynamic pricing and learning problem within a Bayesian framework. On of the first is Aoki (1973), who applies methods from stochastic adaptive control theory. He considers a setting where the demand function depends on unknown parameters, which are learned by the decision maker in a Bayesian fashion. The purpose is to minimize (a function of) the excess demand. He shows how the optimal Bayesian policy can, in theory, be computed via dynamic programming, but that in many situations no closed-form analytical expression of the solution exists. He then proposes two approximation policies. In the first, certainty equivalent pricing (CEP), at each decision moment the price is chosen that would be optimal if the current parameter estimates were correct. In the second, called an approximation under static price expectation, the firm acts at each decision moments as if the chosen price will be maintained throughout the remainder of the selling period. Aoki (1974) shows that the prices generated by these policies converge a.s. to the optimal price.

Similar work is done by Chong and Cheng (1975), under more restrictive assumptions of a linear demand function with two unknown parameters and normally distributed disturbance terms. They show how to calculate the optimal pricing policy using a dynamic programming approach. If the intercept is known, the optimal price is of the certainty equivalent type, but this is not the case if both the intercept and slope are unknown. Three algorithms are proposed to approximate the optimal price, and the performance of two of these - CEP, and a policy based on adaptive dual control theory - are compared with each other by means of simulations.

Closely related Bayesian studies are Nguyen (1984, 1997), Lobo and Boyd (2003) and Qu et al. (2013). Nguyen (1984) considers a quantity-setting monopolist firm facing random demand in multiple periods, where the demand function depends on an unknown parameter which is learned by the firm in a Bayesian fashion. Structural properties of the optimal policy are derived, and its performance is compared with a myopic one-period policy. Nguyen (1997, Section 5) discusses these questions in the context of a price-setting monopolist. Lobo and Boyd (2003) consider the same setting as Chong and Cheng (1975), and compare by means of a computer simulation the performance of four pricing policies with each other. Qu et al. (2013) assume Bernoulli distributed demand with expectation a logit function of price, with a normal prior on the unknown parameters. Because this distributional form hampers exact calculation of posterior distributions, the authors discuss how to calculate an approximation. They propose a Bayesian-greedy price policy which cannot be computed exactly either, and show how an approximation can be calculated. A numerical study focusing on performance on a short time horizon compares the pricing policies with a number of alternatives.

Cope (2007) assumes that the firm only picks prices from a finite set of predetermined selling prices. This allows for a discretization of the reservation-price distribution of customers, and the construction of a general Dirichlet prior. In theory an optimal price strategy can be calculated by dynamic programming, but in practice this is computationally intractable. The author develops approximations for the value function in the dynamic program, and numerically compares the performance of the resulting pricing heuristics with CEP. In addition, he shows that his pricing 
heuristics converge to the optimal price if an average-reward criterion is used, and that their performance do not suffer much from a misspecified prior distribution. Leloup and Deveaux (2001) also assume that the firm chooses from a finite set of prices. They formulate the pricingand-learning problem as a multi-armed bandit problem with Bernoulli distributed arms, and use approximations to Gittins index policies to circumvent the computational problems associated with solving the full Bayesian dynamic program.

Manning (1979) and Venezia (1984) are two related studies that focus on optimal design of market research. Manning (1979) considers a monopolist firm facing a finite number of customers. By doing market research, the firm can ask $n$ potential customers about their demand at some price $p$. Such market research is not for free, and the main question of the paper is to determine the optimal amount of market research. This setting is closely related to pricing rules that split the selling season in two parts (e.g. the first pricing rule proposed by Witt (1986)): in the first phase, price experimentation takes place in order to learn the unknown parameters, and in the second phase of the selling season, the myopic price is used. Venezia (1984) considers a linear demand model with unknown parameters, one of which behaves like a random walk. The firm learns about these parameters using Bayes' rule. In addition, the firm can learn the true current value of this random walk by performing market research (which costs money). The author shows how the optimal market-research policy can be obtained from a dynamic program.

A common theme in the references mentioned above is that it is often intractable to compute the optimal Bayesian policy, and that therefore approximations are necessary. Rothschild (1974) points to a more fundamental problem of the Bayesian framework. He assumes that there are only two prices the firm can choose, with demand for each price Bernoulli distributed with unknown mean. The dynamic pricing problem is thus viewed as a two-armed bandit problem. The optimal Bayesian policy can be computed via the corresponding dynamic programming formulation. The key result of Rothschild (1974) is that, under the optimal Bayesian strategy, with positive probability the price sequences converges to a price that (with hindsight) is not the optimal price. McLennan (1984) derives a similar conclusion in a related setting: the set of admissible prices is continuous, and the relation between price and expected demand is one of two known linear demand curves. It turns out that, under an optimal Bayesian policy, the sequence of prices may converge with positive probability to a price different from the optimal price. This work is extended by Harrison et al. (2012), who show that in several instances a myopic Bayesian policy may lead to such "incomplete learning". They propose two modifications of the myopic Bayesian policy that avoid incomplete learning, and prove bounds on their performance. Afèche and Ata (2013) derive incompletelearning results of similar flavor in the context of pricing different types of customers in an $M / M / 1$ queue.

All studies mentioned above assume that the firm is risk-neutral and optimizes the expected revenue. Sun and Abbas (2013) depart from this assumption by studying the optimal price in a Bayesian dynamic-pricing-and-learning problem with a risk-averse seller. Another variant is considered by Wang et al. (2013), whose study departs from the stationary demand assumption and is related to the papers discussed in Section 3.1.3. The authors consider pricing of subscriptionbased information goods, and assume that the demand intensity over the life cycle of the product 
behaves as the density function of a Weibull distribution. The parameters of this Weibull distribution are unknown, and learned in a Bayesian fashion using a dynamic-programming formulation and application of Monte Carlo simulation techniques. Choi et al. (2012) study a family of simple pricing policies, in a Bayesian setting, based on separating the finite time horizon in an exploration and exploitation phase. They calculate the optimal risk-averse price with respect to a number of risk measures, and provide numerical examples.

The economics and econometrics literature also contains several studies on joint pricing and Bayesian learning. Prescott (1972), Grossman et al. (1977), Mirman et al. (1993a) consider twoperiod models and study the necessity and effects of price experimentation. Trefler (1993) focuses on the direction of experimentation, and applies his results on several pricing problems. Rustichini and Wolinsky (1995) and Keller and Rady (1999) consider a setting where the market environment changes in a Markovian fashion between two known demand functions, and study properties of optimal experimentation. Balvers and Cosimano (1990) consider a dynamic pricing model where the coefficients of a linear demand model change over time. Willems (2012) aims to explain observed discreteness in price data. The author considers a model where the expected demand depends linearly on price via two time-varying parameters with known expectation. The author elaborates a Bayesian learning approach via dynamic programming, and discusses the differences between active and passive learning. Easley and Kiefer (1988), Kiefer and Nyarko (1989), Aghion et al. (1991) are concerned with Bayesian learning in general stochastic control problems with uncertainty. They study the possible limits of Bayesian belief vectors, and show that in some cases these limits may differ from the true value. This implies that active experimentation is necessary to obtain strongly consistent control policies.

\subsubsection{Non-Bayesian approaches}

Despite the disadvantages of the Bayesian framework outlined above (computational intractability of the optimal solution, the results by Rothschild (1974) and McLennan (1984) on incomplete learning), it has taken several decades before pricing policies in a non-Bayesian setting where studied. An early exception is Aoki (1974), who proposes a pricing scheme based on stochastic approximation in a non-Bayesian framework. He proves that the prices converge almost surely to the optimal price, and compares the policy with Bayesian pricing schemes introduced in Aoki (1973).

More recent work in a non-Bayesian context is Carvalho and Puterman (2005a,b). They propose a so-called one-step ahead pricing policy: based on a Taylor expansion of the expected revenue for the next period, the price is chosen that approximately maximizes the sum of the revenues in the next two periods. This is in contrast to certainty equivalent pricing, where only the expected revenue of the next period is maximized. In Carvalho and Puterman (2005a), this idea is applied to a binomial demand distribution with expectation a logit function of the price. By means of a simulation, the performance of the policy is compared with CEP, and with a variant of CEP where each period with a certain time-dependent probability a random price is chosen. In Carvalho and Puterman (2005b), a log-normal demand distribution is assumed, and three more pricing policies are considered in the simulation. Morales-Enciso and Branke (2012) consider a similar setting for 
a multimodal market, propose two new pricing heuristics, and compare these numerically with some of the policies in Carvalho and Puterman (2005a,b).

A disadvantage of the many pricing heuristics that have been proposed in the literature, both in a Bayesian and a non-Bayesian setting, is that a qualitative statement of their performance is often missing. In many studies the performance of pricing policies is only evaluated numerically, without any analytical results. This changes with the work of Kleinberg and Leighton (2003), who quantify the performance of a pricing policy by $\operatorname{Regret}(T)$ : the expected loss in $T$ time periods incurred by not choosing optimal prices. They consider a setting where buyers arrive sequentially to the firm, and buy only if their willingness-to-pay (WtP) exceeds the posted price. Under some additional assumptions, they show that if the $\mathrm{WtP}$ of the individual buyers is an i.i.d. sample of a common distribution, then there is no pricing policy that achieves $\operatorname{Regret}(T)=o(\sqrt{T})$; in addition, there is a pricing policy that achieves $\operatorname{Regret}(T)=O(\sqrt{T \log (T)})^{1}$. In an adversarial or worst-case setting, where the $\mathrm{WtP}$ of individual buyers is not assumed to be i.i.d., they show that no pricing policy can achieve $\operatorname{Regret}(T)=o\left(T^{2 / 3}\right)$, and that there is a pricing policy with $\operatorname{Regret}(T)=O\left(T^{2 / 3} \log (T)^{1 / 3}\right)$.

The proof that no policy can achieve regret $o(\sqrt{T})$ is quite involved and requires many assumptions on the demand function. Broder and Rusmevichientong (2012) show a $\sqrt{T}$ lower bound on the regret in a different setting, with Bernoulli distributed demand depending on two unknown parameters. The proof makes use of information-theoretic inequalities and techniques found in Besbes and Zeevi (2011). They also provide a pricing policy that exactly achieves regret $\sqrt{T}$ growth rate. Their policy separates the time horizon in 'exploration periods', during which two fixed experimentation prices are used, and 'exploitation periods', during which the price is used that is optimal w.r.t. parameter estimates derived from data from the exploration periods. If there is only a single unknown parameter, and in addition the demand curve satisfies a certain "well-separated assumption", they show that there is a policy with $\operatorname{Regret}(T)=O(\log (T))$. The intuition behind this well-separated condition is that it excludes uninformative prices: prices at which the expected demand given a certain parameter estimate is equal to the true expected demand. The existence of such prices appear to play an important role in the best achievable growth rate of the regret; see also the discussion on the subject (in a Bayesian setting) in Harrison et al. (2012).

den Boer and Zwart (2010) study dynamic pricing and learning for a broad class of demand functions and distributions, where unknown parameters are estimated with quasi-likelihood estimation. They show that a certainty equivalent pricing policy is not strongly consistent, by showing in an example that the limit of the price sequence is with positive probability different from the optimal price. They propose a pricing policy that always chooses the price closest to the certainty equivalent price, but such that a certain amount of price dispersion is guaranteed. The price dispersion, measured by the sample variance of the selling prices, influences the quality of the parameter estimates, and by carefully tuning the growth rate of the price dispersion, they achieve a price policy with $\operatorname{Regret}(T)=O\left(T^{1 / 2+\delta}\right)$, for arbitrary small $\delta>0$. In a multi-product setting this is improved by den Boer $(2011)$ to $\operatorname{Regret}(T)=O(\sqrt{T \log T})$.

\footnotetext{
${ }^{1}$ Here $f(T)=O(g(T))$ means $\sup _{T \in \mathbb{N}} f(T) / g(T)<\infty$, and $f(T)=o(g(t))$ means $\lim \sup _{T \rightarrow \infty} f(T) / g(T)=0$, when $f$ and $g$ are functions on $\mathbb{N}$.
} 
Assuming a linear demand function with normally distributed disturbance terms, Keskin and Zeevi (2013) show a $\sqrt{T}$ lower bound on the regret, using other proof techniques than Broder and Rusmevichientong (2012). In addition, generalizing Broder and Rusmevichientong (2012) and den Boer and Zwart (2010), they formulate sufficient conditions for any pricing policy to achieve $\operatorname{Regret}(T)=O(\sqrt{T} \log T)$. They furthermore study a setting where the expected demand at a certain price is exactly known to the seller, and prove performance bounds on pricing policies. Tehrani et al. (2012) assume that the demand model lies in a finite set of known demand functions. This enables them to formulate the dynamic pricing problem as a multi-armed bandit with dependent arms. They propose a pricing policy based on the likelihood-ratio test, and show that its regret is bounded assuming that there are no uninformative prices.

A closely related pricing problem is studied by Jia et al. (2013), who consider dynamic pricing and learning in an electricity market. A retailer controls the price of electricity for customers who participate in a demand response program, and tries to determine the price that minimizes the difference between real and anticipated demand. The expected consumer demand is a linear function of price, with unknown parameters that are learned using a stochastic-approximation type policy inspired by Lai and Robbins (1982). The authors show a $O(\log T)$ bound on the regret, and show that no policy can achieve sub-logarithmic regret. The fact that logarithmic instead of $\sqrt{T}$ regret can be achieved seems to be caused by the similarities with the multi-period control problem (Taylor, 1974, Anderson and Taylor, 1976). The objective in this latter problem is to steer the expected output of a linear function to a desired level. Although closely related to optimal pricing, there are some subtle differences discussed in den Boer and Zwart (2010, Remark 1), that cause the different attainable regret rates.

Eren and Maglaras (2010) study dynamic pricing in a robust optimization setting. They show that if an infinite number of goods can be sold during a finite time interval, it is optimal to use a price-skimming strategy. They also study settings where learning of the demand function occurs, but under the rather strong assumption that observed demand realizations are without noise. Bergemann and Schlag $(2008,2011)$ and Handel et al. (2013) also consider pricing in a robust framework, but their setting is static instead of dynamic. Handel and Misra (2013) consider a two-period model where a monopolist sets prices based on a non-parametric set of demand curves feasible with acquired sales data. The authors describe and analyze the optimal two-period pricing policy that minimizes a dynamic version of the minimax regret, and show that dynamic learning will lead to smaller introductory price relative to a static environment.

Pricing without demand information in a queueing model is studied by Haviv and Randhawa (2012). They consider the problem of pricing delay-sensitive customers in an unobservable $\mathrm{M} / \mathrm{M} / 1$ queue. The purpose of the paper is to study the impact of ignoring arrival-rate information on the optimal pricing strategy. The authors find that a policy that ignores this information performs surprisingly well, and in some cases can still capture $99 \%$ of the optimal revenue. 


\subsection{Finite inventory}

We here discuss the literature on dynamic pricing and learning in the presence of a finite inventory that cannot be replenished. Most of the studies assume a finite selling season, corresponding to the models discussed in Section 3.2.1. Some studies however assume an infinite time horizon, and consider the objective of maximizing total discounted reward.

\subsubsection{Early work}

Lazear (1986) considers a simple model where a firm sells one item during at most two periods. In the first period a number of customers visit the store; if none of them buys the item, the firm adapts its prior belief on the value of the product, updates the selling price, and tries to sell the item in the second period. The author shows that the expected profit increases by having two selling periods instead of one. He extends his model in several directions, notably by allowing strategic behavior of customers who may postpone their purchase decision if they anticipate a price decrease. Sass (1988) extends the model of Lazear and studies the relation between the optimal price strategy and the number of potential buyers.

\subsubsection{Bayesian approaches}

Aviv and Pazgal (2005b) start a research stream on Bayesian learning in dynamic pricing with finite inventory. Customers arrive according to a Poisson process; once arrived, the probability of purchasing an item is determined by a reservation price distribution. For reasons of tractability this distribution is assumed to be known and exponentially decreasing in the selling price. The unknown arrival rate is learned via Bayesian updates of a prior belief. After explicitly stating the optimal pricing policy in the full information case, the authors characterize the optimal pricing scheme in the incomplete-information case by means of a differential equation. This equation does not always admit an explicit analytical solution, and therefore three pricing heuristics are proposed: a certainty equivalent pricing (CEP) heuristic, a fixed price policy, and a naive pricing policy that ignores uncertainty on the market. Numerical experiments suggest that CEP performs quite well. An almost identical setting is studied by Lin (2006), who proposes a pricing policy and evaluates its performance via simulations.

Sen and Zhang (2009) extend the model of Aviv and Pazgal (2005b) by assuming that the purchase probabilities of arriving customers are not known to the firm. They assume that the demand distribution is an element of a finite known set, and consider a discrete-time setting with Bayesian learning and a gamma prior on the arrival rate. The optimal pricing policy can be explicitly calculated, and, in an extensive computational study, its performance is compared with both a full information setting and a setting where no learning occurs.

Araman and Caldentey (2009) and Farias and van Roy (2010) study a closely related problem where a firm sells a finite amount of non-perishable inventory during an infinite time horizon. The purpose is to maximize cumulative expected discounted revenues. Similar to Aviv and Pazgal 
(2005b), they both assume that customers arrive according to a Poisson process with unknown rate, and that arriving customers buy a product according to their reservation price, the distribution of which is known to the firm. The unknown arrival rate is learned via Bayesian updates of the prior distribution. Araman and Caldentey (2009) consider a two-point prior distribution, whereas Farias and van Roy (2010) assume that the prior is a finite mixture of gamma distributions; in both settings, the posterior distributions are in the same parametric family as the prior, which makes the problem tractable. Araman and Caldentey (2009) propose a pricing heuristic based on an asymptotic approximation of the value function of the corresponding intensity control problem. They compare its performance numerically with CEP, static pricing, and a two-price policy. Farias and van Roy (2010) propose another heuristic, called decay balancing, and show several numerical experiments that suggest that it often performs better than both the heuristic proposed by Araman and Caldentey (2009) and CEP. In addition they prove a performance bound on decay balancing, showing that the resulting expected discounted revenue is always at least one third of the optimal value. They also discuss an extension to a setting with multiple stores that may use different selling prices. Mason and Välimäki (2011) consider a seller of a single item in an infinite time horizon, with maximizing the expected discounted reward as objective criterion. Potential buyers arrive as a Poisson process with either high or low intensity; the seller learns the true value of the arrival intensity in a Bayesian fashion. The authors study structural properties of the price path.

A slightly different but related setting is studied by Aviv and Pazgal (2005a). They consider a seller of finite inventory during a finite selling season, where the demand function changes according to an underlying Markov chain. Both the finite state space of this Markov chain and the demand functions associated with each state are known to the firm. The current state of the system is unknown to the seller, but it is learned via Bayesian learning based on observed demand realizations. By including this Bayesian belief vector into the state space of the dynamic pricing problem, the authors obtain a Markov decision problem with full information, which can in theory be solved. Computationally it is intractable, however, and therefore several approximate solutions are discussed. Chen (2012) considers a similar partially observable Markov decision process (POMDP) as Aviv and Pazgal (2005a). In his setting, the seller estimates the willingnessto-pay distribution of customers based on two-sided censored observations. Three near-optimal price heuristics are proposed and their performance is assessed by numerical experiments. For exponentially or Weibull distributed demand, more refined results on the behavior of the heuristics are obtained.

\subsubsection{Non-Bayesian approaches}

Bertsimas and Perakis (2006) consider dynamic pricing and learning of a finite inventory in a non-Bayesian setting. They assume a linear demand model with normally distributed noise terms and unknown slope, intercept and variance. These parameters are estimated using least-squares linear regression. The authors formulate a dynamic program that, in theory, can provide the optimal pricing policy. The large size of the state space makes the problem computationally intractable, however, and the authors study different approximate solutions. They also consider dynamic pricing and learning in a oligopolistic environment, where in addition the price elasticity 
of demand is slowly varying over time. They discuss methods for estimating the demand of the firm and of its competitors, mention several methods of determining the selling prices, and provide a small computational study.

Besbes and Zeevi (2009) propose a pricing algorithm for both a parametric and non-parametric setting, and consider the objective of optimizing the minimax regret. They consider an asymptotic regime, where both initial inventory and demand go to infinity at equal speed. In both a parametric and non-parametric setting they provide an upper bound on the minimax regret attained by their proposed pricing policy, and a lower bound on the minimax regret that is attained by any policy. Wang et al. (2011) improve some of these bounds, and Besbes and Zeevi (2012) extend Besbes and Zeevi (2009) to a setting where multiple products share the same finite resources. Another variant of the problem is studied by Besbes and Maglaras (2012), who study the situation where certain financial milestone constraints in terms of sales and revenues targets are imposed. They formulate a pricing policy and study its performance in an asymptotic regime, where inventory, sales horizon, and revenue and sales target grow to infinity at equal speed.

den Boer and Zwart (2011b) do not consider this asymptotic regime where inventory and demand grow to infinity, but instead study a setting with multiple, consecutive, finite selling seasons. They show that the system satisfies a certain endogenous learning property, which causes certainty equivalent pricing to be a consistent policy. This means that no active price experimentation is necessary to learn the demand function - except possibly finitely many times at the beginning of the time horizon. The authors prove upper and lower bounds on the achievable regret, and illustrate their results by several numerical experiments.

In Babaioff et al. (2012), a firm tries to sell $k$ items to $n$ potential customers. The authors propose an online pricing-and-learning policy that does not require parametric assumptions on the demand distribution, and that exploits the fact that the problem is closely related to multi-armed bandit problems (despite the finite inventory, which means that the optimal price depends on the current inventory level). They show a regret bound of $O\left((k \log n)^{2 / 3}\right)$, and provide a matching lower bound on the regret. If the ratio $k / n$ is sufficiently small this bound is improved to $O(\sqrt{k} \log n)$.

A number of studies take a robust approach, where the demand function is not learned over time but assumed to lie in some known uncertainty set. Lim and Shanthikumar (2007) and Thiele (2006) study this in a single-product setting, and Lim et al. (2008), Thiele (2009) in a multiproduct setting. A potential drawback of these robust approaches is that no learning takes place, despite the accumulation of sales data. Lobel and Perakis (2011) attempt to bridge the gap between robust and data-driven approaches to dynamic pricing, by considering a setting where the uncertainty set is deduced from data samples. A robust extension of Araman and Caldentey (2009) and Farias and van Roy (2010), where finite inventory is sold during an infinite time horizon, is studied by Li et al. (2009). Another approach that does not rely on historical demand data is Xiong et al. (2010) (see also Li and Li, 2010, Li et al., 2013). They model demand uncertainty using fuzzy set theory, propose different fuzzy programming models, and present an algorithm based on fuzzy simulation and a genetic algorithm to solve these problems. Finally, Ferrer et al. (2012) assume that demand is a non-random function of price, and lies in an uncertainty set of demand functions known to the decision maker. The authors introduce a measure of risk aversion, 
and study the relation between risk-aversion and properties of the optimal pricing policy, both theoretically and by numerical simulations.

\subsection{Machine-learning approaches}

A considerable stream of literature on dynamic pricing and learning has emerged from the computer science community. In general, the focus of these papers is not to provide a mathematical analysis of the performance of pricing policies, but rather to design a realistic model for electronic markets and subsequently apply machine learning techniques. An advantage of this approach is that one can model many phenomena that influence the demand, such as competition, fluctuating demand, and strategic buyer behavior. A drawback is that these models are often too complex to analyze analytically, and insights on the behavior of various pricing strategies can only be obtained by performing numerical experiments.

Machine-learning techniques that have been applied to dynamic pricing problems include evolutionary algorithms (Ramezani et al., 2011), particle swarm optimization (Mullen et al., 2006), reinforcement learning and Q-learning (Kutschinski et al., 2003, Raju et al., 2006, Könönen, 2006, Chinthalapati et al., 2006, Schwind, 2007, Cheng, 2008, Han et al., Vengerov, 2008, Cheng, 2009, Jintian and Lei, 2009, Han, 2010, Collins and Thomas, 2012), simulated annealing (Xia and Dube, 2007), Markov chain Monte Carlo methods (Chung et al., 2012), the aggregating algorithm (Levina et al., 2009) by Vovk (1990), goal-directed and derivative-following strategies in simulation (DiMicco et al., 2003), neural networks (Brooks et al., 1999, Kong, 2004, Ghose and Tran, 2009, Liu and Wang, 2013), and direct search methods (Brooks et al., 1999, 2001, Kephart et al., 2001, Brooks et al., 2002).

\subsection{Joint pricing and inventory problems}

A few studies consider the problem of simultaneously determining an optimal pricing and inventory replenishment policy while learning about the demand.

Most of them consider learning in a Bayesian framework. Subrahmanyan and Shoemaker (1996) assume that the unknown demand function lies in a finite known set of demand functions, and is learned in a Bayesian fashion. The optimal policy is determined by solving a dynamic program. Several numerical experiments are provided to offer insight in the properties of the pricing policy. Bitran and Wadhwa (1996) and Bisi and Dada (2007) study a similar type of problem, where an unknown parameter is learned in a Bayesian manner, and where the optimal decisions are determined by solving a dynamic program. Bitran and Wadhwa (1996) perform extensive computational experiments, and Bisi and Dada (2007) derive several structural properties of the optimal policy. Lariviere and Porteus (1995) consider the situation of a manufacturer that sells to a retailer. The manufacturer decides on a wholesale price offered to the retailer, and the retailer has to choose an optimal inventory replenishment policy. Both learn about a parametrized demand function in a Bayesian fashion. Properties of the optimal policy, both for the manufacturer and the retailer, are studied. Gaul and Azizi (2010) assume that a product is sold in different stores. 
The problem is to determine optimal prices in a finite number of periods, as well as to decide if and how inventory should be reallocated between stores. Parameters of the demand function are learned by Bayesian updating, and numerical experiments are provided to illustrate the method.

Burnetas and Smith (2000) consider a joint pricing and inventory problem in a non-parametric setting. They propose an adaptive stochastic-approximation policy, and show that the expected profit per period converges to the optimal profit under complete information. A robust approach to the dynamic pricing and inventory control problem with multiple products is studied by Adida and Perakis (2006). The focus of that paper is the formulation of the robust optimization problem, and to study its complexity properties. Related is the work of Petruzzi and Dada (2002). These authors assume that there is no demand noise, which means that the unknown parameters that determine the demand function are completely known once a demand realization is observed that does not lead to stock-out. Adida and Perakis (2010a) discuss several robust and stochastic optimization approaches to joint pricing and procurement under demand uncertainty, and compare these approaches with each other in a numerical study.

\section{Methodologically Related Areas}

Dynamic pricing under uncertainty is closely related to multi-armed bandit problems. This is a class of problems that capture many essential features of optimization problems under uncertainty, including the well-known exploration-exploitation trade-off: the decision maker should properly balance the two objectives of maximizing instant reward (exploitation of current knowledge) and learning the unknown properties of the system (exploration). This trade-off between learning and instant optimization is also frequently observed in dynamic pricing problems. The literature on multi-armed bandit problems is large; some key references are Thompson (1933), Robbins (1952), Lai and Robbins (1985), Gittins (1989), Auer et al. (2002); see further Vermorel and Mohri (2005), Cesa-Bianchi and Lugosi (2006), Powell (2010). If in a dynamic pricing problem the number of admissible selling prices is finite, the problem can be modeled as a classical multiarmed bandit problem. This approach is e.g. taken by Rothschild (1974), Xia and Dube (2007), and Cope (2007). If the set of admissible selling prices is a continuum, then the dynamic pricing problem is closely related to the continuum-armed bandit problem. This problem has recently been studied, among others, by Kleinberg (2005), Auer et al. (2007), Cope (2009), Wang et al. (2009), Rusmevichientong and Tsitsiklis (2010), Filippi et al. (2010), Abbasi-Yadkori et al. (2011), and Yu and Mannor (2011). Pricing and learning in a time-varying market, as discussed in Section 6.4, is related to the non-stationary multi-armed bandit problem (Garivier and Moulines, 2011).

Another important area related to dynamic pricing and learning is the study of convergence rates of statistical estimates. Lai and Wei (1982) study how the speed of convergence of least-squares linear regression estimates depend on the amount of dispersion in the explanatory variables. Their results are applied in several dynamic pricing problems with linear demand functions, such as Le Guen (2008) and Cooper et al. (2012). Similarly, results on the convergence rate of maximum-likelihood estimators, as in Borovkov (1998) and den Boer and Zwart (2011a), are crucial in the analysis of pricing policies by Besbes and Zeevi (2011), Broder and Rusmevichientong (2012) and den Boer 
and Zwart (2010).

Dynamic pricing and learning can also be put in a general framework of stochastic control problems with parametric uncertainty. For various dynamic economic models, such problems have been by considered by Easley and Kiefer (1988), Kiefer and Nyarko (1989), Marcet and Sargent (1989), Wieland (2000a,b), Beck and Wieland (2002), Han et al. (2006), amongst many others. Kendrick et al. (2008) review some of this literature, focussing on continuous-time optimal control problems with linear system equations, quadratic cost functions, and Gaussian additive noise terms.

Clearly, many sequential optimization problems in operations research that are studied in an online-learning setting have methodological similarities with dynamic pricing and learning: inventory control (Scarf, 1959, Azoury, 1985, Huh et al., 2011, is just a small sample of the vast literature), online advertisement (e.g. Nazerzadeh et al., 2013), assortment planning (e.g. Caro and Gallien, 2007, Rusmevichientong et al., 2010, Sauré and Zeevi, 2013), et cetera. These problems can also be studied in conjunction with optimal pricing. For example, Talebian et al. (2013) study simultaneous pricing and assortment optimization with Bayesian demand learning, and Section 4.4 lists a number of studies that combine pricing and inventory control in an incomplete-information setting.

\section{Extensions and New Directions}

Most of the literature discussed above studies dynamic pricing and learning for a monopolist firm that sells a single product to nonstrategic customers in a stationary market environment. Many extensions to this setting are possible, and we here list a number of them.

\subsection{Multiple products}

A number of recent papers depart from the single-product setting, and study pricing and learning for multiple types of products. The demand for each product does not only depend on its own selling price, but also on the selling prices of substitute or complementary products.

Models with infinite inventory are studied by Le Guen (2008), den Boer (2011), and Keskin and Zeevi (2013). The master's thesis by Le Guen (2008) considers a linear demand model, where the unknown parameter matrices are of a particular structure. He proposes a pricing algorithm that is equal to certainty equivalent pricing, except that at certain predetermined exploration periods a small discount of the certainty equivalent price is offered. The prices are shown to converge to the optimal prices. For non-linear demand functions, a pricing heuristic is proposed. den Boer (2011) considers multi-product pricing for a broad class of demand functions. The unknown parameters of the demand function can be estimated with quasi-likelihood estimation. He proposes a pricing policy that at each time period chooses the perceived optimal price, but with a constraint that guarantees a lower bound on a measure of price dispersion. By carefully tuning the growth rate of the price dispersion the policy is shown to achieve $\operatorname{Regret}(T)=O\left(T^{2 / 3}\right)$. For a specific class of demand functions (so-called canonical link functions), this bound is improved to $\operatorname{Regret}(T)=$ 
$O(\sqrt{T \log (T)})$. Keskin and Zeevi (2013) prove a $\sqrt{T}$ lower bound on the regret achievable by any policy in a multi-product setting. In addition they consider a class of so-called orthogonal price policies, and provide conditions under which they satisfy $\operatorname{Regret}(T)=O(\sqrt{T} \log T)$.

Models with finite inventory are considered by Besbes and Zeevi (2012), Gallego and Talebian (2012) and Lim et al. (2008). Besbes and Zeevi (2012) extend Besbes and Zeevi (2009) to a setting where multiple products share the same finite resources. Their algorithm divides the sales horizon in an exploration period and an exploitation period. During the exploration period different equally spread prices are tried; during the exploitation periods, selling prices are used that are optimal w.r.t. estimates based on the exploration periods. They show in an asymptotic regime where demand and inventory grow to infinity how to balance the length of the exploration and exploitation periods, and derive corresponding bounds on the regret. Gallego and Talebian (2012) consider a setting where during a finite sales horizon a finite number of products is offered in multiple versions. Demand is modeled by a customer choice model. The different productversions share an unknown 'core value', which is estimated by maximum likelihood estimation based on accumulating sales data. The possible time-varying arrival rate of customers is learned in a Bayesian fashion. The authors develop a pricing rule in a rolling horizon framework, and illustrate its behavior by a computational study. Finally, a robust optimization approach to multi-product pricing under demand uncertainty is studied by Lim et al. (2008).

\subsection{Strategic consumer behavior}

The importance of incorporating the effect of strategically behaving customers on the dynamic pricing policy has been recognized by many studies; cf. the papers on dynamic pricing with strategic customer behavior mentioned in Section 3.2.1. The study of optimal pricing with both strategic customer behavior and demand learning by the seller, however, is not that well developed. (Learning by consumers in these type of models is considered, e.g., by Liu and van Ryzin, 2011, Swinney, 2011).

Loginova and Taylor (2008) consider a stylized two-period model where a seller tries to sell a single item to a single, strategically behaving buyer. The seller has a prior belief on the willingness-topay of the buyer, assumed to be either "high" or "low", and this belief is updated via Bayes' rule after observing the outcome of the first period. The authors characterize game-theoretic equilibria, and study what happens if a buyer strategically decides not to buy in the first period in order to anticipate a lower price in the second period. Taylor (2004) considers a model closely related to Loginova and Taylor (2008), but focuses on questions regarding consumer privacy and the value of customer information. Mersereau and Zhang (2012) also consider a two-period model in which a fraction of the customers acts strategically. The seller knows the aggregate demand distribution, but not the fraction of strategically behaving customers. The authors propose a robust pricing policy and prove bounds on its performance. These results suggest that good performance of pricing policies may be possible without knowing all characteristics of the strategic behavior of customers. In Levina et al. (2009), a seller learns about a complicated demand process that incorporates strategic customer behavior. This behavior is described using a game-theoretic 
consumer choice model. The focus of the paper is on properties and numerical performance of an online-learning algorithm suitable for the complicated process considered by the authors.

\subsection{Competition}

Several studies address dynamic pricing and learning in a competitive environment.

Fishman and Gandal (1994) consider a simple two-period duopoly model, building forth on Rothschild (1974). The unknown reservation price of customers is one of two known values, which are learned by the firms in a Bayesian framework. Unsuccessful price experiments in the first time period may negatively influence the profit in the second time period. The authors show that, for some problem instances, the unique subgame-perfect equilibrium strategy is for both firms not to experiment, whereas some amount of price experimentation would be optimal in the monopolist setting. Coughlan and Mantrala (1994), elaborating upon Coughlan and Mantrala (1992), consider an alternating-moves duopoly where a firm learns the pricing policy of the competitor in a Bayesian fashion. The authors analyze properties of the equilibria resulting from this repeated game, and compare these with a full-information setting and to the equilibria resulting from collusive behavior. Choi and Jagpal (2004) consider a duopoly-pricing model with a linear demand model and unknown parameters, and in addition assume that firms are risk-averse. They study by a computer simulation the effect of risk aversion and parameter uncertainty on the firms' pricing behavior, and on the difference between a Stackelberg game and a Nash game.

Bertsimas and Perakis (2006) consider an oligopolistic market with a finite selling season. Several firms compete for a single, perishable product, with finite or infinite capacities. The true demand function is a linear function of the selling prices of all firms, with unknown parameters that are slowly varying over time, and with Gaussian noise terms added. The unknown parameters are estimated using data from a finite number of recent observations; based on these estimates, a firm predicts the competitors' prices in the next period by solving an optimization problem which assumes that all firms price optimally. The firm then determines its next selling price by maximizing expected revenue over the remaining time horizon, assuming its parameter estimates are correct. Some computational examples are provided to illustrate the results. A related study is Kachani et al. (2007). They consider multiple quantity-setting firms selling the same type of products. The price-demand relation is linear, with unknown parameters that are allowed to slowly vary over time, and firms have a finite amount of inventory. The authors formulate the optimization problem as a mathematical program with equilibrium constraints, provide some computational results, and derive a closed-form expression of a limiting Nash equilibrium in case of two firms and a selling horizon of two time periods.

Cooper et al. (2012) focus on the question what happens if firms wrongly assume that they are monopolistic, while in fact competitors are present. The authors study the dynamics of selling prices and parameter estimates in repeated pricing games, and identify settings under which the price sequence converge to a Nash equilibrium. They also consider situations where the selling prices do neither converge to the Nash equilibrum nor to the cooperative solution, and where in addition the limit depends on the initial prices. 
Kwon et al. (2009) formulate a finite-time finite-capacity oligopolistic pricing problem in the language of differential variational inequalities. They consider a demand model where the timederivative of demand is proportional to the difference between a firm's price and a moving average of prices used in the past. Unknown model parameters are estimated with a Kalman filter, which is recalculated at several moments in the sales horizon. The authors propose an algorithm to solve the resulting differential variational inequalities, and illustrate their method by a numerical example. Related to the set-up of Kwon et al. (2009) is the recent study by Chung et al. (2012), who consider a state-space model for dynamic pricing and learning in an oligopoly. They also assume that expected demand depends on the difference between a posted price and a reference price, which is computed as a weighted moving average of historical prices. The time-derivative of the expected demand is proportional to this difference, and depends furthermore on a parameter which evolves as a time-series and which is estimated using a non-parametric functional-coefficient autoregressive model, making use of a Markov chain Monte Carlo algorithm. Numerical examples are provided to show the efficiency and robustness of the algorithm.

A robust optimization approach to dynamic pricing in an oligopolistic environment with demand uncertainty is taken by Perakis and Sood (2006) (see also the closely related recent study Friesz et al., 2012). They consider a multi-period setting with fixed, finite inventory levels, and study Nash equilibrium price policies. Adida and Perakis (2010b) consider a joint pricing-and-inventory control problem with duopolistic competition and demand uncertainty, and formulate it as a robust optimization problem. The authors discuss existence and uniqueness of a Nash equilibrium and address various computational aspects of the problem.

A large stream of economics literature is concerned with the long-term behavior of price adjustment processes in oligopolistic settings, cf. Kirman (1975), Aghion et al. (1993), Mirman et al. (1993b), Harrington (1995), Bergemann and Valimaki (1996), Alepuz and Urbano (1999), Rassenti et al. (2000), Belleflamme and Bloch (2001), Schinkel et al. (2002), Keller and Rady (2003), Dimitrova and Schlee (2003), Tuinstra (2004). One usually assumes that firms are using a certain specific learning scheme, and then studies whether the selling prices converge to a Nash equilibrium. While these papers are interesting from a perspective of understanding price formation, application in business practice is hampered by the fact that one generally does not know which learning scheme competing firms are using. A remarkable early study on pricing and learning in a competitive environment is Barta and Varaiva (1976), who study convergence properties of various stochasticapproximation based price-adjustment rules.

Contributions from the computer science community to dynamic pricing with demand uncertainty in a competitive environment include Greenwald and Kephart (1999) and Dasgupta and Das (2000) (in a setting with pricebots and shopbots). These studies consider a particular model, propose pricing policies, and study their performance via numerical simulations.

\subsection{Time-varying market parameters}

Recently some studies are appearing that depart from the strong assumption of unchanging market conditions. 
Besbes and Zeevi (2011) study a pricing problem where the willingness-to-pay (WtP) distribution of the customers changes at some unknown point in time. The WtP distribution before and after the change is assumed to be known, only the time of change is unknown to the seller. Lower bounds on the worst-case regret are derived, and pricing strategies are developed that achieve the order of these bounds. Besbes and Sauré (2012) is a recent study on the classical finite-inventory pricing model that allows for changes in the demand function. The authors prove structural properties of the problem of optimally hedging against abrupt changes in the demand function. Chen and Farias (2013) also study pricing in a finite-inventory setting where the market process is fluctuating over time. They propose a pricing heuristic which is based on the idea of frequently re-calculating the optimal fixed price. The authors prove bounds on the performance loss relative to an optimal clairvoyant pricing strategy in an asymptotic regime where inventory and demand grows large.

Infinite-inventory settings are studied by Braouezec (2008) and den Boer (2012). Braouezec (2008) considers a non-stationary multi-armed bandit as model for a monopoly pricing problem, where the non-stationarity is caused by the fact that not only the firm but also consumers are learning about the product on sale. For different assumptions on the knowledge available to the monopolist, different learning rules are proposed and evaluated by numerical simulations. In den Boer (2012), the firm estimates a fluctuating market process by a weighted least-squares estimator, and optimizes the weight in a min-max optimal sense with respect to certain assumptions made in advance by the seller. Tight upper bounds on the average regret are provided, and the methodology is illustrated by two examples: pricing in the Bass model of a product life-cycle, and pricing in a competitive environment.

Some of the economics / econometrics papers mentioned at the end of Section 4.1.2 also assume time-varying demand parameters.

\section{Conclusion}

Dynamic pricing with incomplete demand information is a topic that has received considerable research attention in recent years. Different scientific communities have studied characteristics of pricing policies, usually with different aims in mind: the operations research / management science literature typically focuses on finding an optimal pricing policy from the perspective of a seller, and on proving optimality properties in tractable models; the economics literature is generally more concerned with explaining price behavior and price formation observed in markets; and the computer science literature is typically not afraid to consider complicated demand models that are not tractable for mathematical analysis, but that can be handled using appropriate machine learning techniques. In spite of these different aims, there is much in overlap in the studied demand models, proposed pricing policies, and the techniques deployed to analyze the behavior of these policies. In this survey we aim at providing a comprehensive overview of the many studies on this topic arising from these different scientific communities. 


\section{Acknowledgments}

Part of this work was written while the author was affiliated with Centrum Wiskunde \& Informatica (CWI), Eindhoven University of Technology, and University of Amsterdam. This survey is a considerable extension of the literature review in chapter 2 of den Boer (2013).

\section{References}

Y. Abbasi-Yadkori, D. Pal, and C. Szepesvári. Improved algorithms for linear stochastic bandits. In J. Shawe-Taylor, R. S. Zemel, P. Bartlett, F. C. N. Pereira, and K. Q. Weinberger, editors, Advances in Neural Information Processing Systems 24, pages 2312-2320, 2011.

E. Adida and G. Perakis. A robust optimization approach to dynamic pricing and inventory control with no backorders. Mathematical Programming, Series B, 107(1):97-129, 2006.

E. Adida and G. Perakis. Dynamic pricing and inventory control: robust vs. stochastic uncertainty models - a computational study. Annals of Operations Research, 181:125-157, 2010a.

E. Adida and G. Perakis. Dynamic pricing and inventory control: Uncertainty and competition. Operations Research, 58(2):289-302, 2010b.

P. Afèche and B. Ata. Bayesian dynamic pricing in queueing systems with unknown delay cost characteristics. Manufacturing \& Service Operations Management, 15(2):292-304, 2013.

P. Aghion, P. Bolton, C. Harris, and B. Jullien. Optimal learning by experimentation. Review of Economic Studies, 58(4):621-654, 1991.

P. Aghion, M. Paz Espinosa, and B. Jullien. Dynamic duopoly with learning through market experimentation. Economic Theory, 3(3):517-539, 1993.

H. S. Ahn, M. Gümüş, and P. Kaminsky. Pricing and manufacturing decisions when demand is a function of prices in multiple periods. Operations Research, 55(6):1039-1057, 2007.

M. Dolores Alepuz and A. Urbano. Duopoly experimentation: Cournot competition. Mathematical Social Sciences, 37(2):165-188, 1999.

T. W. Anderson and J. B. Taylor. Some experimental results on the statistical properties of least squares estimates in control problems. Econometrica, 44(6):1289-1302, 1976.

M. Aoki. On a dual control approach to the pricing policies of a trading specialist. In R. Conti and A. Ruberti, editors, 5th Conference on Optimization Techniques Part II, volume 4 of Lecture Notes in Computer Science, chapter 24, pages 272-282. Springer, Berlin, Heidelberg, 1973.

M. Aoki. On some price adjustment schemes. Annals of Economic and Social Measurement, 3(1):95-115, 1974 .

V. F. Araman and R. Caldentey. Dynamic pricing for nonperishable products with demand learning. Operations Research, 57(5):1169-1188, 2009.

V. F. Araman and R. Caldentey. Revenue management with incomplete demand information. In J. J. Cochran, editor, Encyclopedia of Operations Research. Wiley, 2011.

P. Auer, N. Cesa-Bianchi, and P. Fischer. Finite-time analysis of the multi-armed bandit problem. Machine Learning, 47(2):235-256, 2002.

P. Auer, R. Ortner, and C. Szepesvári. Improved rates for the stochastic continuum-armed bandit problem. In N. Bshouty and C. Gentile, editors, Learning Theory, volume 4539 of Lecture Notes in Computer Science, pages 454-468. Springer Berlin Heidelberg, 2007. 
Y. Aviv and A. Pazgal. A partially observed Markov decision process for dynamic pricing. Management Science, 51(9):1400-1416, 2005a.

Y. Aviv and A. Pazgal. Pricing of short life-cycle products through active learning. Working paper, 2005b.

Y. Aviv and A. Pazgal. Optimal pricing of seasonal products in the presence of forward-looking consumers. Manufacturing \& Service Operations Management, 10(3):339-359, 2008.

Y. Aviv and G. Vulcano. Dynamic list pricing. In Özer and R. Phillips, editors, The Oxford Handbook of Pricing Management, chapter 23. Oxford University Press, London, 2012.

K. S. Azoury. Bayes solution to dynamic inventory models under unknown demand distribution. Management Science, 31(9):1150-1160, 1985.

M. Babaioff, L. Blumrosen, S. Dughmi, and Y. Singer. Posting prices with unknown distributions. In Innovations in Computer Science (ICS) 2011, pages 166-178, 2011.

M. Babaioff, S. Dughmi, R. Kleinberg, and A. Slivkins. Dynamic pricing with limited supply. http: //arxiv.org/pdf/1108.4142v2.pdf, 2012.

J. Baetge, G. Bolenz, W. Ballwieser, R. Hömberg, and P. Wullers. Dynamic price policies in monopolistic competition. In J. Rose and C. Bilciu, editors, Modern Trends in Cybernetics and Systems. Proceedings of the Third International Congress of Cybernetics and Systems, Bucharest, Romania, August 25-29, 1975, volume 1, pages 401-417. Springer Verlag, 1977.

P. Bajari and C. L. Benkard. Demand estimation with heterogeneous consumers and unobserved product characteristics: a hedonic approach. Journal of Political Economy, 113(6):1239-1276, 2005.

R. J. Balvers and T. F. Cosimano. Actively learning about demand and the dynamics of price adjustment. The Economic Journal, 100(402):882-898, 1990.

R. Baptista. The diffusion of process innovations: a selective review. International Journal of the Economics of Business, 6(1):107-129, 1999.

D. P. Baron. Price uncertainty, utility, and industry equilibrium in pure competition. International Economic Review, 11(3):463-480, 1970.

D. P. Baron. Demand uncertainty in imperfect competition. International Economic Review, 12(2): 196-208, 1971.

S. Barta and P. Varaiva. Microeconomics: stochastic models of price adjustment. In S. V. Berg, editor, Annals of Economic and Social Measurement, volume 5(3), pages 267-281. National Bureau of Economic Research, 1976.

F. M. Bass. A new product growth for model consumer durables. Management Science, 15(5):215-227, 1969.

W. J. Baumol and R. E. Quandt. Rules of thumb and optimally imperfect decisions. The American Economic Review, 54(2):23-46, 1964.

G. W. Beck and V. Wieland. Learning and control in a changing economic environment. Journal of Economic Dynamics and Control, 26(9-10):1359-1377, 2002.

P. Belleflamme and F. Bloch. Price and quantity experimentation: a synthesis. International Journal of Industrial Organization, 19(10):1563-1582, 2001.

R. Benini. Sull'uso delle formole empiriche a nell'economia applicata. Giornale degli economisti, 2nd series, 35:1053-1063, 1907.

D. Bergemann and K. H. Schlag. Pricing without priors. Journal of the European Economic Association, 6(2-3):560-569, 2008.

D. Bergemann and K. H. Schlag. Robust monopoly pricing. Journal of Economic Theory, 146(6):25272543, 2011. 
D. Bergemann and J. Valimaki. Market experimentation and pricing. Cowles Foundation Discussion Paper $1122,1996$.

D. Bergemann and J. Välimäki. Market diffusion with two-sided learning. The RAND Journal of Economics, 28(4):773-795, 1997.

S. Berry, J. Levinsohn, and A. Pakes. Automobile prices in market equilibrium. Econometrica, 63(4): 841-890, 1995.

D. Bertsimas and G. Perakis. Dynamic pricing: a learning approach. In Mathematical and Computational Models for Congestion Charging, pages 45-79. Springer, New York, 2006.

O. Besbes and C. Maglaras. Dynamic pricing with financial milestones: feedback-form policies. Management Science, to appear, 2012.

O. Besbes and D. Sauré. Dynamic pricing strategies in the presence of demand shocks. Working paper, 2012 .

O. Besbes and A. Zeevi. Dynamic pricing without knowing the demand function: risk bounds and nearoptimal algorithms. Operations Research, 57(6):1407-1420, 2009.

O. Besbes and A. Zeevi. On the minimax complexity of pricing in a changing environment. Operations Research, 59(1):66-79, 2011.

O. Besbes and A. Zeevi. Blind network revenue management. Operations Research, to appear, 2012.

M. Bhalla. Dynamic pricing under social learning with strategic consumers. Working paper No. 367, 2012.

F. Billström and S. A. O. Thore. Simulation experiments with dynamic price strategies in monopoly theory. In H. O. A. Wold, editor, Econometric model building. Essays on the Causal Chain Approach, pages 297-321. North Holland Publishing Co., Amsterdam, 1964.

F. Billström, H. Laadi, S. A. O. Thore, L. O. Friberg, and O. Johansson. Some experiments with dynamization of monopoly models. 16th Meeting of the Econometric Society in Uppsala, 1954.

A. Bisi and M. Dada. Dynamic learning, pricing, and ordering by a censored newsvendor. Naval Research Logistics, 54(4):448-461, 2007.

G. Bitran and R. Caldentey. An overview of pricing models for revenue management. Manufacturing 86 Service Operations Management, 5(3):203-230, 2003.

G. Bitran, R. Caldentey, and S. Mondschein. Coordinating clearance markdown sales of seasonal products in retail chains. Operations Research, 46(5):609-624, 1998.

G. R. Bitran and S. V. Mondschein. Periodic pricing of seasonal products in retailing. Management Science, 43(1):64-79, 1997.

G. R. Bitran and H. K. Wadhwa. A methodology for demand learning with an application to the optimal pricing of seasonal products. Working paper, WP\#3898-96, 1996.

A. Borovkov. Mathematical Statistics. Gordon and Breach Science Publishers, Amsterdam, 1998.

S. Bose, G. Orosel, M. Ottaviani, and L. Vesterlund. Dynamic monopoly pricing and herding. The RAND Journal of Economics, 37(4):910-928, 2006.

Y. Braouezec. Stochastic adaptive dynamics of a simple market as a non-stationary multi-armed bandit problem. Social Science Research Network Working Paper Series, 2008.

J. Broder and P. Rusmevichientong. Dynamic pricing under a general parametric choice model. Operations Research, 60(4):965-980, 2012.

C. H. Brooks, S. Fay, R. Das, J. K. MacKie-Mason, J. O. Kephart, and E. H. Durfee. Automated strategy searches in an electronic goods market: Learning and complex price schedules. In Proceedings of the 1st ACM conference on Electronic commerce, pages 31-40. ACM, 1999. 
C. H. Brooks, R. Das, J. O. Kephart, J. K. MacKie-Mason, and R. S. Gazzale. Information bundling in a dynamic environment. Technical report, Society for Computational Economics, 2001.

C. H. Brooks, R. S. Gazzale, R. Das, J. O. Kephart, J. K. MacKieMason, and E. H. Durfee. Model selection in an information economy: Choosing what to learn. Computational Intelligence, 18(4):566-582, 2002.

A. Brown and A. Deaton. Surveys in applied economics: models of consumer behaviour. The Economic Journal, 82(328):1145-1236, 1972.

A. N. Burnetas and C. E. Smith. Adaptive ordering and pricing for perishable products. Operations Research, 48(3):436-443, 2000.

G. P. Cachon and R. Swinney. Purchasing, pricing, and quick response in the presence of strategic consumers. Management Science, 55(3):497-511, 2009.

R. Caminal and X. Vives. Price dynamics and consumer learning. Journal of Economics ES Management Strategy, 8(1):95-131, 1999.

F. Caro and J. Gallien. Dynamic assortment with demand learning for seasonal consumer goods. Management Science, 53(2):276-292, 2007.

A. X. Carvalho and M. L. Puterman. Learning and pricing in an internet environment with binomial demand. Journal of Revenue and Pricing Management, 3(4):320-336, 2005a.

A. X. Carvalho and M. L. Puterman. Dynamic optimization and learning: How should a manager set prices when the demand function is unknown? Technical report, Instituto de Pesquisa Economica Aplicada - IPEA, Discussion Papers 1117, 2005b.

N. Cesa-Bianchi and G. Lugosi. Prediction, learning, and games. Cambridge University Press, New York, 2006.

L. Chan, Z. Shen, and D. Simchi-Levi. Coordination of pricing and inventory decisions: a survey and classification. In D. Simchi-Levi, D. Wu, and Z. Shen, editors, Handbook of Quantitative Supply Chain Analysis: Modeling in the E-Business Era, pages 335-392. Springer, New York, 2004.

L. Chen. Dynamic pricing with active learning under two-sided censoring. Working paper, The Fuqua School of Business, Duke University, 2012.

X. Chen and D. Simchi-Levi. Joint pricing and inventory management. In Özer and R. Phillips, editors, The Oxford Handbook of Pricing Management, chapter 30. Oxford University Press, London, 2012.

Y. Chen and V. F. Farias. Simple policies for dynamic pricing with imperfect forecasts. Operations Research, 61(3):612-624, 2013.

Y. M. Chen and D. C. Jain. Dynamic monopoly pricing under a Poisson-type uncertain demand. The Journal of Business, 65(4):593-614, 1992.

R. Chenavaz, L. P. Carrier, L. Etienne, and C. Paraschiv. Dynamic pricing in management science. Journal of Economics Studies and Research, 2011, 2011.

Y. Cheng. Dynamic pricing decision for perishable goods: a Q-learning approach. In Wireless Communications, Networking and Mobile Computing, 2008. WiCOM'08. 4th International Conference on, pages 1-5. IEEE, 2008.

Y. Cheng. Real time demand learning-based Q-learning approach for dynamic pricing in E-retailing setting. In Information Engineering and Electronic Commerce IEEC '09. International Symposium on, pages 594-598, 2009.

V. L. R. Chinthalapati, N. Yadati, and R. Karumanchi. Learning dynamic prices in MultiSeller electronic retail markets with price sensitive customers, stochastic demands, and inventory replenishments. Systems, Man, and Cybernetics, Part C: Applications and Reviews, IEEE Transactions on, 36(1):92-106, 2006. 
S. Chan Choi and S. Jagpal. Duopoly pricing under risk aversion and parameter uncertainty. Journal of Product \& Brand Management, 13(5):359-368, 2004.

T. M. Choi, P. S. Chow, and T. Xiao. Electronic price-testing scheme for fashion retailing with information updating. International Journal of Production Economics, 140(1):396-406, 2012.

C. Y. Chong and D. Cheng. Multistage pricing under uncertain demand. In S. V. Berg, editor, Annals of Economic and Social Measurement, volume 4(2), pages 311-323. NBER, 1975.

C. F. Christ. Early progress in estimating quantitative economic relationships in America. The American Economic Review, 75(6):39-52, 1985.

S. Christ. Operationalizing Dynamic Pricing Models: Bayesian Demand Forecasting and Customer Choice Modeling for Low Cost Carriers. PhD thesis, 2011.

B. D. Chung, J. Li, T. Yao, C. Kwon, and T. L. Friesz. Demand learning and dynamic pricing under competition in a state-space framework. Engineering Management, IEEE Transactions on, 59(2):240249,2012 .

D. G. Clarke and R. J. Dolan. A simulation analysis of alternative pricing strategies for dynamic environments. The Journal of Business, 57(1):S179-S200, 1984.

F. Clarke, M. N. Darrough, and J. Heineke. Optimal pricing policy in the presence of experience effects. The Journal of Business, 55(4):517-530, 1982.

R. W. Clower. Some theory of an ignorant monopolist. The Economic Journal, 69(276):705-716, 1959.

A. Collins and L. Thomas. Comparing reinforcement learning approaches for solving game theoretic models: a dynamic airline pricing game example. Journal of the Operational Research Society, 63: $1165-1173,2012$.

W. L. Cooper, T. Homem de Mello, and A. J. Kleywegt. Learning and pricing with models that do not explicitly incorporate competition. Working paper, 2012.

E. Cope. Bayesian strategies for dynamic pricing in e-commerce. Naval Research Logistics, 54(3):265-281, 2007.

E. W. Cope. Regret and convergence bounds for a class of continuum-armed bandit problems. IEEE Transactions on Automatic Control, 54(6):1243-1253, 2009.

A. T. Coughlan and M. K. Mantrala. Dynamic competitive pricing strategies. International Journal of Research in Marketing, 9(1):91-108, 1992.

A. T. Coughlan and M. K. Mantrala. Dynamic competitive retail pricing behavior with uncertainty and learning. Managerial and Decision Economics, 15(1):3-20, 1994.

A. A. Cournot. Researches into the Mathematical Principles of the Theory of Wealth. Translated in 1897 by N.T. Bacon, with a bibliography of Mathematical Economics by Irving Fisher. The Macmillan Company, New York, 1838.

J. Creedy. On the King-Davenant "law" of demand. Scottish Journal of Political Economy, 33(3):193-212, 1986.

P. Dasgupta and R. Das. Dynamic pricing with limited competitor information in a multi-agent economy, volume 1901 of Lecture Notes in Computer Science, pages 299-310. Springer Berlin Heidelberg, 2000.

C. Davenant. An essay upon the probable methods of making a people gainers in the balance of trade. James Knapton, London, 1699.

A. de Palma, R. Lindsey, and S. Proost. Research challenges in modelling urban road pricing: an overview. Transport Policy, 13(2):97-105, 2006.

I. Deksnyte and Z. Lydeka. Dynamic pricing and its forming factors. International Journal of Business and Social Science, 3(23):213-220, 2012. 
A. V. den Boer. Dynamic pricing with multiple products and partially specified demand distribution. Submitted for publication, 2011.

A. V. den Boer. Tracking the market: Dynamic pricing and learning in a changing environment. Submitted for publication, 2012 .

A. V. den Boer. Dynamic Pricing and Learning. PhD thesis, Vrije Universiteit Amsterdam, 2013.

A. V. den Boer and B. Zwart. Simultaneously learning and optimizing using controlled variance pricing. Management Science, Accepted for publication, 2010.

A. V. den Boer and B. Zwart. Mean square convergence rates for maximum quasi-likelihood estimators. Submitted for publication, 2011a.

A. V. den Boer and B. Zwart. Dynamic pricing and learning with finite inventories. Submitted for publication, 2011b.

J. M. DiMicco, P. Maes, and A. Greenwald. Learning curve: a simulation-based approach to dynamic pricing. Electronic Commerce Research, 3(3-4):245-276, 2003.

M. Dimitrova and E. E. Schlee. Monopoly, competition and information acquisition. International Journal of Industrial Organization, 21(10):1623-1642, 2003.

D. Easley and N. M. Kiefer. Controlling a stochastic process with unknown parameters. Econometrica, 56(5):1045-1064, 1988.

J. Eliashberg and R. Steinberg. Marketing-production joint decision-making. In J. Eliashberg and J. D. Lilien, editors, Management Science in Marketing, Handbooks in Operations Research and Management Science, volume 5, pages 827-880. North Holland Publishing Co., Amsterdam, 1993.

W. Elmaghraby and P. Keskinocak. Dynamic pricing in the presence of inventory considerations: research overview, current practices, and future directions. Management Science, 49(10):1287-1309, 2003.

W. Elmaghraby, A. Gülcü, and P. Keskinocak. Designing optimal pre-announced markdowns in the presence of rational customers with multi-unit demands. Manufacturing $\&$ Service Operations Management, 10(1):126-148, 2008.

S. S. Eren and C. Maglaras. Monopoly pricing with limited demand information. Journal of Revenue and Pricing Management, 9:23-48, 2010.

G. C. Evans. The dynamics of monopoly. The American Mathematical Monthly, 31(2):77-83, 1924.

G. C. Evans. The mathematical theory of economics. The American Mathematical Monthly, 32(3):104-110, 1925.

R. W. Farebrother. Early explorations in econometrics. In T. C. Mills and K. Patterson, editors, Palgrave Handbook of Econometrics, Volume 1: Econometric Theory. Palgrave MacMillan, Basingstoke, 2006.

V. F. Farias and B. van Roy. Dynamic pricing with a prior on market response. Operations Research, 58 (1):16-29, 2010.

A. Federgruen and A. Heching. Combined pricing and inventory control under uncertainty. Operations Research, 47(3):454-475, 1999.

Y. Feng and G. Gallego. Optimal starting times for end-of-season sales and optimal stopping times for promotional fares. Management Science, 41(8):1371-1391, 1995.

Y. Feng and G. Gallego. Perishable asset revenue management with Markovian time dependent demand intensities. Management Science, 46(7):941-956, 2000.

Y. Feng and B. Xiao. Optimal policies of yield management with multiple predetermined prices. Operations Research, 48(2):332-343, 2000a. 
Y. Feng and B. Xiao. A continuous-time yield management model with multiple prices and reversible price changes. Management Science, 46(5):644-657, 2000b.

J. C. Ferrer, D. Oyarzún, and J. Vera. Risk averse retail pricing with robust demand forecasting. International Journal of Production Economics, 136(1):151-160, 2012.

G. Fibich, A. Gavious, and O. Lowengart. Explicit solutions of optimization models and differential games with nonsmooth (asymmetric) reference-price effects. Operations Research, 51(5):721-734, 2003.

S. Filippi, O. Cappe, A. Garivier, and C. Szepesvari. Parametric bandits: The generalized linear case. In J. Lafferty, C. K. I. Williams, J. Shawe-Taylor, R. S. Zemel, and A. Culotta, editors, Advances in Neural Information Processing Systems 23, pages 586-594, 2010.

I. Fisher. Cournot and mathematical economics. The Quarterly Journal of Economics, 12(2):119-138, 1898.

A. Fishman and N. Gandal. Experimentation and learning with networks effects. Economics Letters, 44 (1-2):103-108, 1994.

T. L. Friesz, C. Kwon, T. I. Kim, L. Fan, and T. Yao. Competitive robust dynamic pricing in continuous time with fixed inventories. arXiv:1208.4374, 2012.

G. Gallego and M. Talebian. Demand learning and dynamic pricing for multi-version products. Journal of Revenue and Pricing Management, 11:303-318, 2012.

G. Gallego and G. van Ryzin. Optimal dynamic pricing of inventories with stochastic demand over finite horizons. Management Science, 40(8):999-1020, 1994.

G. Gallego and G. van Ryzin. A multiproduct dynamic pricing problem and its applications to network yield management. Operations Research, 45(1):24-41, 1997.

A. Garcia, E. Campos-Nañez, and J. Reitzes. Dynamic pricing and learning in electricity markets. 53(2): 231-241, 2005.

A. Garivier and E. Moulines. On upper-confidence bound policies for switching bandit problems algorithmic learning theory. In J. Kivinen, C. Szepesvári, E. Ukkonen, and T. Zeugmann, editors, Algorithmic Learning Theory. 22nd International Conference, ALT 2011, Espoo, Finland, October 5-7, 2011, volume 6925 of Lecture Notes in Computer Science, chapter 16, pages 174-188. Springer Berlin / Heidelberg, Berlin, Heidelberg, 2011.

W. Gaul and A. D. Azizi. A demand learning data based approach to optimize revenues of a retail chain. In H. Locarek-Junge and C. Weihs, editors, Classification as a Tool for Research, Studies in Classification, Data Analysis, and Knowledge Organization, chapter 75, pages 683-691. Springer, Berlin, Heidelberg, 2010.

T. K. Ghose and T. T. Tran. Dynamic pricing in electronic commerce using neural network. In G. Babin, P. Kropf, and M. Weiss, editors, E-Technologies: Innovation in an Open World, volume 26, pages 227-232. Springer Berlin Heidelberg, 2009.

C. Gini. Prezzi e consumi. Giornale degli Economisti, 3rd series, 40:99-114, 235-249, 1910.

J. C. Gittins. Multi-armed bandit allocation indices. Wiley-Interscience series in Systems and Optimization. Wiley, New York, 1989.

J. Gönsch, R. Klein, and C. Steinhardt. Dynamic pricing - State-of-the-Art. Zeitschrift für Betriebswirtschaft, Ergänzungsheft 3 'Operations Research in der Betriebswirtschaft', pages 1-40, 2009.

J. Gönsch, R. Klein, M. Neugebauer, and C. Steinhardt. Dynamic pricing with strategic customers. Journal of Business Economics, to appear, 2012.

E. A. Greenleaf. The impact of reference price effects on the profitability of price promotions. Marketing Science, 14(1):82-104, 1995. 
A. R. Greenwald and J. O. Kephart. Shopbots and pricebots. In A. Moukas, C. Sierra, and F. Ygge, editors, Agent Mediated Electronic Commerce II, pages 1-23. Springer, 1999.

S. J. Grossman, R. E. Kihlstrom, and L. J. Mirman. A Bayesian approach to the production of information and learning by doing. The Review of Economic Studies, 44(3):533-547, 1977.

J. Han, T. L. Lai, and V. Spivakovsky. Approximate policy optimization and AdaptiveControl in regression models. Computational Economics, 27(4):433-452, 2006.

W. Han. A dynamic pricing algorithm by Bayesian Q-learning. In Computer Modeling and Simulation, 2010. ICCMS '10. Second International Conference on, volume 2, pages 515-519, 2010.

W. Han, L. Liu, and H. Zheng. Dynamic pricing by multiagent reinforcement learning. In Electronic Commerce and Security, 2008 International Symposium on, pages 226-229.

B. Handel and K. Misra. Robust new product pricing. Working paper, http://ssrn.com/abstract= 2307991, 2013.

B. R. Handel, K. Misra, and J. W. Roberts. Robust firm pricing with panel data. Journal of Econometrics, 174(2):165-185, 2013.

B. Hansen. Report of the Uppsala meeting, August 2-4, 1954. Econometrica, 23(2):198-216, 1955.

J. E. Harrington. Experimentation and learning in a differentiated-products duopoly. Journal of Economic Theory, 66(1):275-288, 1995.

M. Harris and A. Raviv. A theory of monopoly pricing schemes with demand uncertainty. The American Economic Review, 71(3):347-365, 1981.

J. M. Harrison, N. B. Keskin, and A. Zeevi. Bayesian dynamic pricing policies: learning and earning under a binary prior distribution. Management Science, 58(3):570-586, 2012.

M. Haviv and R. S. Randhawa. Pricing in queues without demand information. Available at http: //ssrn. com/abstract=1940993, 2012.

E. R. Hawkins. Methods of estimating demand. Journal of Marketing, 21(4):428-438, 1957.

A. Heching and Y. T. Leung. Product pricing in the e-business era. In C. An and H. Fromm, editors, Supply Chain Management on Demand, chapter 4, pages 65-96. 2005.

P. Heidhues and B. Köszegi. The impact of consumer loss aversion on pricing. CEPR Discussion Paper No. 4849, 2005.

J. R. Hicks. Annual survey of economic theory: the theory of monopoly. Econometrica, 3(1):1-20, 1935.

S. L. Horner, C. F. Roos, V. von Szeliski, A. T. Court, and S. M. DuBrul. The Dynamics of Automobile Demand. General Motors Corporation, New York, 1939.

W. T. Huh, R. Levi, P. Rusmevichientong, and J. B. Orlin. Adaptive data-driven inventory control with censored demand based on kaplan-meier estimator. Operations Research, 59(4):929-941, 2011.

B. Ifrach, C. Maglaras, and M. Scarsini. Monopoly pricing in the presence of social learning. Working paper, 2012.

L. Jia, Q. Zhao, and L. Tong. Retail pricing for stochastic demand with unknown parameters: an online machine learning approach. In 2013 Allerton Conference on Communication, Control and Computing, 2013.

W. Jintian and Z. Lei. Application of reinforcement learning in dynamic pricing algorithms. In Automation and Logistics, 2009. ICAL '09. IEEE International Conference on, pages 419-423, 2009.

S. Kachani, G. Perakis, and C. Simon. Modeling the transient nature of dynamic pricing with demand learning in a competitive environment. In T. L. Friesz, editor, Network Science, Nonlinear Science and Infrastructure Systems, volume 102 of International Series in Operations Research $\&$ Management Science, pages 223-267. Springer US, 2007. 
S. Kalish. Monopolist pricing with dynamic demand and production cost. Marketing Science, 2(2):135-159, 1983.

B. Kamrad, S. S. Lele, A. Siddique, and R. J. Thomas. Innovation diffusion uncertainty, advertising and pricing policies. European Journal of Operational Research, 164(3):829-850, 2005.

S. Karlin and C. R. Carr. Prices and optimal inventory policies. In K. Arrow, S. Karlin, and H. Scarf, editors, Studies in Applied Probability and Management Science, pages 159-172. Stanford University Press, Stanford, 1962.

G. Keller and S. Rady. Optimal experimentation in a changing environment. The Review of Economic Studies, 66(3):475-507, 1999.

G. Keller and S. Rady. Price dispersion and learning in a dynamic differentiated-goods duopoly. The RAND Journal of Economics, 34(1):138-165, 2003.

D. A. Kendrick, H. M. Amman, and M. P. Tucci. Learning about learning in dynamic economic models, 2008.

J. O. Kephart, C. H. Brooks, R. Das, J. K. MacKie-Mason, R. Gazzale, and E. H. Durfee. Pricing information bundles in a dynamic environment. In Proceedings of the 3rd ACM conference on Electronic Commerce, pages 180-190, 2001.

N. B. Keskin and A. Zeevi. Dynamic pricing with an unknown linear demand model: asymptotically optimal semi-myopic policies. Working paper, http://faculty.chicagobooth.edu/bora.keskin/pdfs/ DynamicPricingUnknownDemandModel.pdf, 2013.

N. M. Kiefer and Y. Nyarko. Optimal control of an unknown linear process with learning. International Economic Review, 30(3):571-586, 1989.

W. M. Kincaid and D. A. Darling. An inventory pricing problem. Journal of Mathematical Analysis and Applications, 7:183-208, 1963.

A. P. Kirman. Learning by firms about demand conditions. In R. Day, editor, Adaptive Economics. Academic Press, 1975.

R. Kleinberg. Nearly tight bounds for the continuum-armed bandit problem. In L. K. Saul, Y. Weiss, and L. Bottou, editors, Advances in Neural Information Processing Systems 17, pages 697-704, 2005.

R. Kleinberg and T. Leighton. The value of knowing a demand curve: bounds on regret for online postedprice auctions. In Proceedings of the 44th IEEE Symposium on Foundations of Computer Science, pages 594-605, 2003

A. J. Kleywegt. An optimal control problem of dynamic pricing. Working paper, 2001.

D. Kong. One dynamic pricing strategy in agent economy using neural network based on online learning. In WI '04 Proceedings of the 2004 IEEE/WIC/ACM International Conference on Web Intelligence, pages $98-102,2004$.

V. Könönen. Dynamic pricing based on asymmetric multiagent reinforcement learning. Issue International Journal of Intelligent Systems International Journal of Intelligent Systems, 21(1):73-98, 2006.

P. K. Kopalle, A. G. Rao, and J. L. Assunção. Asymmetric reference price effects and dynamic pricing policies. Marketing Science, 15(1):60-85, 1996.

E. Kutschinski, T. Uthmann, and D. Polani. Learning competitive pricing strategies by multi-agent reinforcement learning. Journal of Economic Dynamics and Control, 27(11-12):2207-2218, 2003.

C. Kwon, T. L. Friesz, R. Mookherjee, T. Yao, and B. Feng. Non-cooperative competition among revenue maximizing service providers with demand learning. European Journal of Operational Research, 197(3): 981-996, 2009.

T. L. Lai and H. Robbins. Iterated least squares in multiperiod control. Advances in Applied Mathematics, 3:50-73, 1982. 
T. L. Lai and H. Robbins. Asymptotically efficient adaptive allocation rules. Advances in Applied Mathematics, 6:4-22, 1985.

T. L. Lai and C. Z. Wei. Least squares estimates in stochastic regression models with applications to identification and control of dynamic systems. The Annals of Statistics, 10(1):154-166, 1982.

M. A. Lariviere and E. L. Porteus. Manufacturer-retailer contracting under an unknown demand distribution. Working paper, 1995.

E. P. Lazear. Retail pricing and clearance sales. The American Economic Review, 76(1):14-32, 1986.

T. Le Guen. Data-driven pricing. Master's thesis, Sloan School of Management, MIT, 2008.

R. A. Lehfeldt. The elasticity of demand for wheat. The Economic Journal, 24(94):212-217, 1914.

H. E. Leland. Theory of the firm facing uncertain demand. The American Economic Review, 62(3): 278-291, 1972.

Benoît Leloup and Laurent Deveaux. Dynamic pricing on the internet: Theory and simulations. Electronic Commerce Research, 1(3):265-276, 2001.

Y. Levin, J. McGill, and M. Nediak. Dynamic pricing in the presence of strategic consumers and oligopolistic competition. Management Science, 55(1):32-46, 2009.

T. Levina, Y. Levin, J. McGill, and M. Nediak. Dynamic pricing with online learning and strategic consumers: an application of the aggregating algorithm. Operations Research, 57(2):327-341, 2009.

G. Li and W. Li. Dynamic pricing of perishable products with random fuzzy demand. In 2010 International Conference on Management Science \& Engineering, pages 191-199, 2010.

G. Li, Y. Xiong, and Z. Xiong. Robust dynamic pricing over infinite horizon in the presence of model uncertainty. Asia-Pacific Journal of Operational Research, 26(6):779-804, 2009.

G. Li, Z. Xiong, Y. Zhou, and Y. Xiong. Dynamic pricing for perishable products with hybrid uncertainty in demand. Applied Mathematics and Computation, 219(20):10366-10377, 2013.

A. E. B. Lim and J. G. Shanthikumar. Relative entropy, exponential utility, and robust dynamic pricing. Operations Research, 55(2):198-214, 2007.

A. E. B. Lim, J. G. Shanthikumar, and T. Watewai. Robust multi-product pricing. Working paper, http://dx.doi.org/10.2139/ssrn.1078012, 2008.

K. Y. Lin. Dynamic pricing with real-time demand learning. European Journal of Operational Research, 174(1):522-538, 2006.

G. Liu and H. Wang. An online sequential feed-forward network model for demand curve prediction. Journal of Information \& Computational Science, 10(10):3063-3069, 2013.

Q. Liu and G. J. van Ryzin. Strategic capacity rationing to induce early purchases. Management Science, 54(6):1115-1131, 2008.

Q. Liu and G. J. van Ryzin. Strategic capacity rationing when customers learn. Manufacturing ES Service Operations Management, 13(1):89-107, 2011.

R. Lobel and G. Perakis. Dynamic pricing through sampling based optimization. Working paper, 2011.

M. S. Lobo and S. Boyd. Pricing and learning with uncertain demand. Working paper, http://www . stanford.edu/ boyd/papers/pdf/pric_learn_unc_dem.pdf, 2003.

O. Loginova and C. R. Taylor. Price experimentation with strategic buyers. Review of Economic Design, 12(3):165-187, 2008 .

Y. Lou. A unified framework of proactive self-learning dynamic pricing for high-occupancy/toll lanes. Transportmetrica A: Transport Science, 9(3):205-222, 2013. 
V. Mahajan, E. Muller, and F. M. Bass. New product diffusion models in marketing: a review and directions for research. Journal of Marketing, 54(1):1-26, 1990.

R. Manning. Market research by a monopolist: a Bayesian analysis. Economica, 46(183):301-306, 1979.

A. Marcet and T. J. Sargent. Convergence of least squares learning mechanisms in self-referential linear stochastic models. Journal of Economic Theory, 48(2):337-368, 1989.

E. Maskin and J. Riley. Monopoly with incomplete information. The RAND Journal of Economics, 15 (2):171-196, 1984

R. Mason and J. Välimäki. Learning about the arrival of sales. Journal of Economic Theory, 146(4): 1699-1711, 2011.

T. Mazumdar, S. P. Raj, and I. Sinha. Reference price research: review and propositions. Journal of Marketing, 69(4):84-102, 2005.

D. McFadden and K. Train. Mixed MNL models for discrete response. 15:447-470, 2000.

A. McLennan. Price dispersion and incomplete learning in the long run. Journal of Economic Dynamic and Control, 7(3):331-347, 1984.

N. Meade and T. Islam. Modelling and forecasting the diffusion of innovation - a 25-year review. International Journal of Forecasting, 22(3):519-545, 2006.

A. J. Mersereau and D. Zhang. Markdown pricing with unknown fraction of strategic customers. Manufacturing \&S Service Operations Management, 14(3):355-370, 2012.

E. S. Mills. Uncertainty and price theory. The Quarterly Journal of Economics, 73(1):116-130, 1959.

L. J. Mirman, L. Samuelson, and A. Urbano. Monopoly experimentation. International Economic Review, 34(3):549-563, 1993a.

L. J. Mirman, L. Samuelson, and A. Urbano. Duopoly signal jamming. Economic Theory, 3(1):129-149, 1993b.

H. L. Moore. Ecomomic Cycles; Their Law and Cause. The Macmillan Company, New York, 1914.

H. L. Moore. Forecasting the Yield and the Price of Cotton. The Macmillan Company, New York, 1917.

S. Morales-Enciso and J. Branke. Revenue maximization through dynamic pricing under unknown market behaviour. In S. Ravizza and P. Holborn, editors, 3rd Student Conference on Operational Research (SCOR 2012), pages 11-20, 2012.

P. B. Mullen, C. K. Monson, K. D. Seppi, and S. C. Warnick. Particle swarm optimization in dynamic pricing. In 2006 IEEE International Conference on Evolutionary Computation, pages 1232-1239. IEEE, 2006 .

H. Mutlu, M. Alanyali, D. Starobinski, and A. Turhan. Online pricing of secondary spectrum access with unknown demand function. Selected Areas in Communications, IEEE Journal on, 30(11):2285-2294, 2012 .

H. Nazerzadeh, A. Saberi, and R. Vohra. Dynamic pay-per-action mechanisms and applications to online advertising. Operations Research, 61(1):98-111, 2013.

S. Netessine. Dynamic pricing of inventory/capacity with infrequent price changes. European Journal of Operational Research, 174(1):553-580, 2006.

A. J. Nevins. Some effects of uncertainty: simulation of a model of price. The Quarterly Journal of Economics, 80(1):73-87, 1966.

D. Nguyen. The monopolistic firm, random demand, and Bayesian learning. Operations Research, 32(5): 1038-1051, 1984. 
D. Nguyen. Pricing Under Uncertainty, volume 6 of International Series in Quantitative Marketing, chapter 2, pages 23-57. Springer, 1997.

M. Ottaviani. Monopoly pricing with social learning, 1999.

Özer and R. Phillips, editors. The Oxford Handbook of Pricing Management. Oxford University Press, London, 2012.

G. Perakis and A. Sood. Competitive multi-period pricing for perishable products: A robust optimization approach. Mathematical Programming, 107(1):295-335, 2006.

N. C. Petruzzi and M. Dada. Dynamic pricing and inventory control with learning. Naval Research Logistics, 49(3):303-325, 2002.

R. Phillips. Pricing and Revenue Optimization. Stanford University Press, Stanford, CA, 2005.

I. Popescu and Y. Wu. Dynamic pricing strategies with reference effects. Operations Research, 55(3): 413-429, 2007.

W. B. Powell. The knowledge gradient for optimal learning. In J. J. Cochran, editor, Encyclopedia for Operations Research and Management Science. Wiley, New York, 2010.

E. C. Prescott. The multi-period control problem under uncertainty. Econometrica, 40(6):1043-1058, 1972.

H. Qu, I. O. Ryzhov, and M. C. Fu. Learning logistic demand curves in business-to-business pricing. In R. Pasupathy, S. H. Kim, A. Tolk, R. Hill, and M. E. Kuhl, editors, Proceedings of the 2013 Winter Simulation Conference, 2013.

C. V. L. Raju, Y. Narahari, and K. Ravikumar. Learning dynamic prices in electronic retail markets with customer segmentation. Annals of Operations Research, 143:59-75, 2006.

K. Raman and R. Chatterjee. Optimal monopolist pricing under demand uncertainty in dynamic markets. Management Science, 41(1):144-162, 1995.

S. Ramezani, P. A. N. Bosman, and H. La Poutre. Adaptive strategies for dynamic pricing agents. In 2011 IEEE/WIC/ACM International Conferences on Web Intelligence and Intelligent Agent Technology, pages 323-328. IEEE, 2011.

V. R. Rao, editor. Handbook of Pricing Research in Marketing. Edward Elgar, 2009.

S. Rassenti, S. S. Reynolds, V. L. Smith, and F. Szidarovszky. Adaptation and convergence of behavior in repeated experimental cournot games. Journal of Economic Behavior \& Organization, 41(2):117-146, 2000 .

H. Robbins. Some aspects of the sequential design of experiments. Bulletin of the American Mathematical Society, 58(5):527-535, 1952.

B. Robinson and C. Lakhani. Dynamic price models for new-product planning. Management Science, 21 (10):1113-1122, 1975.

C. F. Roos. A mathematical theory of competition. American Journal of Mathematics, 47(3):163-175, 1925.

C. F. Roos. A dynamic theory of economics. Journal of Political Economy, 35(5):632-656, 1927a.

C. F. Roos. Dynamical economics. Proceedings of the National Academy of Sciences of the United States of America, 13(3):145-150, 1927b.

C. F. Roos. Dynamic Economics: Theoretical and Statistical Studies of Demand, Production, and Prices. The Principia Press, Bloomington, 1934. 
M. Roozbehani, M. Dahleh, and S. Mitter. Dynamic pricing and stabilization of supply and demand in modern electric power grids. In Smart Grid Communications (SmartGridComm), 2010 First IEEE International Conference on, pages 543-548, 2010.

M. Rothschild. A two-armed bandit theory of market pricing. Journal of Economic Theory, 9(2):185-202, 1974 .

P. Rusmevichientong and J. N. Tsitsiklis. Linearly parameterized bandits. Mathematics of Operations Research, 35(2):395-411, 2010.

P. Rusmevichientong, Z-J M. Shen, and D. B. Shmoys. Dynamic assortment optimization with a multinomial logit choice model and capacity constraint. Operations Research, 58(6):1666-1680, 2010.

A. Rustichini and A. Wolinsky. Learning about variable demand in the long run. Journal of Economic Dynamics and Control, 19(5-7):1283-1292, 1995.

A. Sandmo. On the theory of the competitive firm under price uncertainty. The American Economic Review, 61(1):65-73, 1971.

T. R. Sass. A note on optimal price cutting behavior under demand uncertainty. The Review of Economics and Statistics, 70(2):336-339, 1988.

D. Sauré and A. Zeevi. Optimal dynamic assortment planning with demand learning. Manufacturing $\mathcal{E}^{\circ}$ Service Operations Management, 15(3):387-404, 2013.

H. Scarf. Bayes solutions of the statistical inventory problem. The Annals of Mathematical Statistics, 30 (2):490-508, 1959

M. P. Schinkel, J. Tuinstra, and D. Vermeulen. Convergence of bayesian learning to general equilibrium in mis-specified models. Journal of Mathematical Economics, 38(4):483-508, 2002.

E. E. Schlee. Buyer experimentation and introductory pricing. Journal of Economic Behavior E Organization, 44(3):347-362, 2001.

H. Schultz. The theory and measurement of demand. University of Chicago Press, Chicago, 1938.

M. Schwind. Dynamic Pricing and Automated Resource Allocation for Complex Information Services, volume 589 of Lecture Notes in Economics and Mathematical Systems. Springer Berlin Heidelberg, 2007.

P. B. Seetharaman. Dynamic pricing. In V. R. Rao, editor, Handbook of Pricing Research in Marketing, chapter 17, pages 384-393. Edward Elgar, 2009.

I. Segal. Optimal pricing mechanisms with unknown demand. American Economic Review, 93(3):509-529, 2003

A. Sen and A. X. Zhang. Style goods pricing with demand learning. European Journal of Operational Research, 196(3):1058-1075, 2009.

Z. M. Shen and X. Su. Customer behavior modeling in revenue management and auctions: A review and new research opportunities. Production and Operations Management, 16(6):713-728, 2007.

M. A. Simaan and T. Takayama. Optimum monopolist control in a dynamic market. IEEE Transactions on Systems, Man, and Cybernetics, 6(12):799-807, 1976.

M. E. Slade. Optimal pricing with costly adjustment: evidence from retail-grocery prices. The Review of Economic Studies, 65(1):87-107, 1998.

A. Smithies. The maximization of profits over time with changing cost and demand functions. Econometrica, 7(4):312-318, 1939.

G. J. Stigler. The early history of empirical studies of consumer behavior. Journal of Political Economy, 62(2):95-113, 1954. 
G. J. Stigler. Henry L. Moore and statistical economics. Econometrica, 30(1):1-21, 1962.

X. Su. Intertemporal pricing with strategic customer behavior. Management Science, 53(5):726-741, 2007.

X. Su. Optimal pricing with speculators and strategic consumers. Management Science, 56(1):25-40, 2010.

S. Subrahmanyan and R. Shoemaker. Developing optimal pricing and inventory policies for retailers who face uncertain demand. Journal of Retailing, 72(1):7-30, 1996.

Z. Sun and A. E. Abbas. Bayesian updating on price elasticity of uncertain demand. In 2013 IEEE International Systems Conference (SysCon), pages 222-228, 2013.

R. Swinney. Selling to strategic consumers when product value is uncertain: the value of matching supply and demand. Management Science, 57(10):1737-1751, 2011.

M. Talebian, N. Boland, and M. Savelsbergh. Pricing to accelerate demand learning in dynamic assortment planning. Working paper. Available at SSRN: http://ssrn. com/abstract=1985979, 2013.

K. T. Talluri and G. J. van Ryzin. The Theory and Practice of Revenue Management. Kluwer Academic Publishers, Boston, 2004.

C. R. Taylor. Consumer privacy and the market for customer information. The RAND Journal of Economics, 35(4):631-650, 2004.

J. B. Taylor. Asymptotic properties of multiperiod control rules in the linear regression model. International Economic Review, 15(2):472-484, 1974.

P. Tehrani, Y. Zhai, and Q. Zhao. Dynamic pricing under finite space demand uncertainty: a multi-armed bandit with dependent arms. arXiv:1206.5345, 2012.

A. Thiele. Single-product pricing via robust optimization. Working paper, 2006.

A. Thiele. Multi-product pricing via robust optimisation. Journal of Revenue and Pricing Management, 8:67-80, 2009.

R. G. Thompson, M. D. George, P. L. Brown, and M. S. Proctor. Optimal production, investment, and output price controls for a monopoly firm of the Evans' type. Econometrica, 39(1):119-129, 1971.

W. R. Thompson. On the likelihood that one unknown probability exceeds another in view of the evidence of two samples. Biometrika, 25(3-4):285-294, 1933.

S. A. O. Thore. Price strategies of an "ignorant" monopolist. In H. O. A. Wold, editor, Econometric model building. Essays on the Causal Chain Approach. North Holland Publishing Co., Amsterdam, 1964.

J. Tinbergen. Bestimmung und deutung von angebotskurven: ein beispiel. Zeitschrift fur Nationalokonomie, 1(5):669-679, 1930.

G. Tintner. Monopoly over time. Econometrica, 5(2):160-170, 1937.

D. Trefler. The ignorant monopolist: optimal learning with endogenous information. International Economic Review, 34(3):565-581, 1993.

T. Tsekeris and S. Voß. Design and evaluation of road pricing: state-of-the-art and methodological advances. NETNOMICS: Economic Research and Electronic Networking, 10(1):5-52, 2009.

J. Tuinstra. A price adjustment process in a model of monopolistic competition. International Game Theory Review, 6(3):417-442, 2004.

I. Venezia. Optimal investments in market research. European Journal of Operational Research, 18(2): 198-207, 1984.

D. Vengerov. A gradient-based reinforcement learning approach to dynamic pricing in partially-observable environments. Future Generation Computer Systems, 24(7):687-693, 2008. 
J. Vermorel and M. Mohri. Multi-armed bandit algorithms and empirical evaluation. In Proceedings of the European Conference of Machine Learning, Porto, Portugal (October 3-7), volume 3720 of Springer Lecture Notes in Computer Science, pages 437-448, 2005.

V. G. Vovk. Aggregating strategies. In Proceedings of the Third Annual Workshop on Computational Learning Theory, COLT '90, pages 371-386, San Francisco, 1990. Morgan Kaufmann Publishers.

Y. Wang, J. Y. Audibert, and R. Munos. Algorithms for infinitely many-armed bandits. In D. Koller, D. Schuurmans, Y. Bengio, and L. Bottou, editors, Advances in Neural Information Processing Systems 21, pages 1729-1736, 2009.

Z. Wang, S. Deng, and Y. Ye. Close the gaps: a learning-while-doing algorithm for a class of single-product revenue management problems. Working paper, 2011.

Z. Wang, S. K. Mukhopadhyay, and D. Q. Yao. Bayesian pricing strategy for information goods. International Journal of Operational Research, 17(4):399-416, 2013.

V. Wieland. Learning by doing and the value of optimal experimentation. Journal of Economic Dynamics and Control, 24(4):501-534, 2000a.

V. Wieland. Monetary policy, parameter uncertainty and optimal learning. Journal of Monetary Economics, 46:199-228, 2000b.

T. Willems. Actively learning by pricing: a model of an experimenting seller. Working paper, https: //sites.google.com/site/twillems85/, 2012.

U. Witt. How can complex economical behavior be investigated? The example of the ignorant monopolist revisited. Behavioral Science, 31(3):173-188, 1986.

P. G. Wright. The tariff on animal and vegetable oils. The Macmillan Company, New York, 1928.

C. H. Xia and P. Dube. Dynamic pricing in e-services under demand uncertainty. Production and Operations Management, 16(6):701-712, 2007.

Y. Xiong, G. Li, and K. J. Fernandes. Dynamic pricing model and algorithm for perishable products with fuzzy demand. Applied Stochastic Models in Business and Industry, 26(6):758-774, 2010.

C. A. Yano and S. M. Gilbert. Coordinated pricing and production/procurement decisions: a review managing business interfaces. In A. K. Chakravarty and J. Eliashberg, editors, Managing Business Interfaces, volume 16 of International Series in Quantitative Marketing, chapter 3, pages 65-103. Springer, New York, 2005.

J. Y. Yu and S. Mannor. Unimodal bandits. In L. Getoor and T. Scheffer, editors, Proceedings of the 28th International Conference on Machine Learning, Bellevue, Washington, USA, pages 41-48, 2011.

E. Zabel. Monopoly and uncertainty. The Review of Economic Studies, 37(2):205-219, 1970.

M. J. Zbaracki, M. Ritson, D. Levy, S. Dutta, and M. Bergen. Managerial and customer costs of price adjustment: direct evidence from industrial markets. 86(2):514-533, 2004.

W. Zhao and Y. S. Zheng. Optimal dynamic pricing for perishable assets with nonhomogeneous demand. Management Science, 46(3):375-388, 2000 . 